\title{
Dynamics of the Antarctic and Arctic mesosphere and lower thermosphere - Part 1: Mean winds
}

\author{
D. J. Sandford ${ }^{1}$, C. L. Beldon ${ }^{1}$, R. E. Hibbins ${ }^{2}$, and N. J. Mitchell ${ }^{1}$ \\ ${ }^{1}$ Department of Electronic and Electrical Engineering, University of Bath, Bath, UK \\ ${ }^{2}$ British Antarctic Survey, Cambridge, UK
}

Received: 15 June 2010 - Published in Atmos. Chem. Phys. Discuss.: 20 July 2010

Revised: 17 October 2010 - Accepted: 19 October 2010 - Published: 4 November 2010

\begin{abstract}
Zonal and meridional winds have been measured in the upper mesosphere and lower thermosphere at polar latitudes using two ground-based meteor radars. One radar is located at Rothera $\left(68^{\circ} \mathrm{S}, 68^{\circ} \mathrm{W}\right)$ in the Antarctic and has been operational since February 2005. The second radar is located at Esrange $\left(68^{\circ} \mathrm{N}, 21^{\circ} \mathrm{E}\right)$ in the Arctic and has been operational since October 1999. Both radars have produced relatively continuous measurements. Here we consider measurements made up to the end of 2009. Both radars are of similar design and at conjugate geographical latitudes, making the results directly comparable and thus allowing investigation of the differences in the mean winds of the Antarctic and Arctic regions. The data from each radar have been used to construct climatologies of monthly-mean zonal and meridional winds at heights between 80 and $100 \mathrm{~km}$. Both Antarctic and Arctic data sets reveal seasonally varying zonal and meridional winds in which the broad pattern repeats from year to year. In particular, the zonal winds display a strong shear in summer associated with the upper part of the westward summertime zonal jet. The winds generally reverse to eastward flow at heights of $\sim 90 \mathrm{~km}$. The zonal winds are eastward throughout the rest of the year. The meridional winds are generally equatorward over both sites, although brief episodes of poleward flow are often evident near the equinoxes and during winter. The strongest equatorward flows occur at heights of $\sim 90 \mathrm{~km}$ during summer.

There are significant differences between the mean winds observed in the Antarctic and Arctic. In particular, the westward winds in summer are stronger and occur earlier in the season in the Antarctic compared with the Arctic. The eastward winds evident above the summertime zonal wind reversal are significantly stronger in the Arctic. The summertime equatorward flow in the Antarctic is slightly weaker, but occurs over a greater depth than is the case in the Arctic.
\end{abstract}

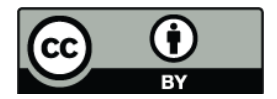

Correspondence to: D. J. Sandford (d.j.sandford@bath.ac.uk)
Comparisons of these observations with those of the URAP and HWM-07 empirical models reveal a number of significant differences. In particular, the zonal winds observed in the Antarctic during wintertime are significantly weaker than those of URAP. However, the URAP zonal winds are a good match to the observations of the Arctic. Significant differences are evident between the observations and HWM-07. In particular, the strong wintertime zonal winds of the Arctic in HWM-07 are not evident in the observations and the summertime zonal winds in HWM-07 are systematically stronger than observed. The agreement with meridional winds is generally poor.

There is a significant amount of inter-annual variability in the observed zonal and meridional winds. Particularly high variability is observed in the Arctic zonal winds in spring and is probably associated with stratospheric warmings.

\section{Introduction}

The dynamics of the mesosphere and lower thermosphere (MLT) are dominated by atmospheric tides, planetary waves, and gravity waves, all of which are superimposed on a background flow, which can itself reach large speeds. These winds, waves and tides are all strongly coupled together. Gravity waves launched from the lower atmosphere dissipate and deposit their energy and momentum into the middle atmosphere. The momentum deposited influences the planetary-scale circulation of the stratosphere and largely drives the planetary-scale circulation of the mesosphere. The momentum deposition in the mesosphere acts to close the middle atmosphere zonal jets and actually reverses the direction of the summertime zonal jet, resulting in strong eastward flows at heights above $\sim 90 \mathrm{~km}$. The momentum deposition also acts with the pressure gradient and Coriolis forces to produce a pole-to-pole meridional circulation. The vertical winds required by continuity considerations to sustain this

Published by Copernicus Publications on behalf of the European Geosciences Union. 
meridional circulation result in an upwelling of air over the summer polar region and a corresponding downwelling of air in the winter polar region. The adiabatic cooing and heating resulting from this vertical motion acts to drive the atmosphere into states far removed from those of pure radiative equilibrium and leads to the well-known cold summer mesopause and the reversed pole-to-pole mesospheric temperature gradient (e.g., McIntyre, 1989; Lieberman, 1999; Holton et al., 2003). This means that there is a strong coupling between the wave dynamics of the mesosphere and the planetary scale circulation and temperature structure. Attempts to understand these coupling processes therefore require accurate determination of the background winds of the mesosphere.

The general circulation and seasonal variability of the MLT at middle and low latitudes has been investigated by ground based radars and satellites. These studies have determined the general characteristics of the zonal and meridional winds of the MLT. In particular, strong zonal wind shears are evident in summer, in which the westward winds of the top of the middle atmosphere zonal jet reverse in the mesosphere to give eastward flows at heights above $\sim 90 \mathrm{~km}$. Associated with this zonal wind reversal in summer is a region of strong equatorward flow in which the meridional winds at heights near $90 \mathrm{~km}$ can reach speeds in excess of $10 \mathrm{~m} \mathrm{~s}^{-1}$. These meridional winds are important in the transport of chemical species (e.g., Plane et al., 1999; Smith, 2004).

In contrast to the situation at middle and low latitudes, there have been relatively few studies of MLT region mean winds at polar latitudes. This is because of the relatively small number of ground based MLT radars deployed at polar latitudes. Nevertheless, in the Arctic MF and Meteor radars have been used to establish a limited number of simple climatologies of the zonal and meridional mean winds. These include the MF radar studies of Portnyagin et al. (1992, 1993, 2004); Dowdy et al. (2001, 2007a); Hall et al. (2003); Kishore et al. (2003) and the meteor radar studies of Hocking (2001); Mitchell et al. (2002); Hall et al. (2003).

Similar to the Arctic there have been few studies made of the mean winds of the Antarctic MLT region. This is largely because of the difficulty in operating ground-based radars for extended intervals in Antarctica. Despite these difficulties, MF and meteor radars have been used to measure the seasonal variability of MLT region mean winds in the Antarctic in a limited number of studies (e.g., Portnyagin et al., 1992, 1993; Vincent, 1994; Dowdy et al., 2001, 2007a; Kishore et al., 2003; Hibbins et al., 2005; Baumgaertner et al., 2005; Merzlyakov et al., 2009).

It is well known that there are significant differences in the mean winds and dynamics of the Arctic and Antarctic stratosphere. For example, the winds of the stratospheric polar vortex are known to be significantly stronger in the Antarctic through strong planetary wave activity (Holton et al., 2003). Another significant difference lies in the gravity wave fluxes of the two polar regions. The mountainous region of the Antarctic peninsula and the southern Andes experience strong prevailing tropospheric westerlies. This generates a localised "hot spot" of intense gravity wave activity and gravity wave fluxes which has no parallel in the Arctic (Wu and Jiang, 2002; Alexander and Teitelbaum, 2007; Baumgaertner and McDonald, 2007). Despite there being significant stratospheric differences, the differences between the polar MLT regions remain poorly understood.

Those studies that have attempted to quantify the differences between the mean winds of the two MLT regions include: Portnyagin et al. (1993), Dowdy et al. (2001, 2007a), Kishore et al. (2003). These studies generally revealed significant differences between the Antarctic and Arctic.

The present study presents mean wind climatologies of the polar MLT region obtained using meteor wind radars located at Rothera $\left(68^{\circ} \mathrm{S}, 68^{\circ} \mathrm{W}\right)$ in the Antarctic and Esrange $\left(68^{\circ} \mathrm{N}, 21^{\circ} \mathrm{E}\right)$ in the Arctic. Datasets of 5 and 10 years are available from the two instruments, respectively, allowing a study of the inter-annual variability in the winds. These two radars are similar in design and are located at conjugate geographical latitudes in each polar region, allowing a comparison of observations free from biases caused by different techniques or small differences in latitude. The use of an identical technique is particularly important because there are known and significant biases between some of the most common techniques used for measuring MLT-region winds (e.g., Meteor and MF radar, Manson et al., 2004). A second companion study, part 2, will report the inter-hemispheric observations of the 12- and 24-h tides, in the MLT region, also using the same two systems.

In Sect. 2 we present a description of the meteor radar data analysis and comparisons between meteor distributions from the two systems used in this study. Section 3 will consider the monthly-mean winds measured over the height range 80$100 \mathrm{~km}$ and compare these with the results of the URAP and HWM-07 mean-wind models. In Sect. 4 we compare the results with those of other studies and review the interhemispheric differences of the observations.

\section{Data analysis}

The first radar used in this study is located at Rothera Base $\left(68^{\circ} \mathrm{S}, 68^{\circ} \mathrm{W}\right)$ on the Antarctic Peninsula. This system has been in continuous operation since its installation in February 2005. The second radar, similar in design to the Rothera radar, is located at Esrange $\left(68^{\circ} \mathrm{N}, 21^{\circ} \mathrm{E}\right)$, near Kiruna in northern Sweden. This system has been in continuous operation since October 1999.

Both radars are commercially-produced SKYiMET meteor-radar systems. Both radars use solid-state transmitters of $6 \mathrm{~kW}$ peak power and operate with a duty cycle of $15 \%$, pulse repetition frequency of $2144 \mathrm{~Hz}$ and a radio frequency of $32.5 \mathrm{MHz}$. Crossed-element Yagi antennas are used for both transmitting and receiving. A single, 
3-element antenna, acts as the transmitter and five separate 2-element antennas as receivers. The radars operate in an all-sky configuration with the radiated power being largely independent of azimuth and maximum gain at $\sim 30^{\circ}$ elevation. Only under-dense echoes are recorded. A detailed description of the systems and data-processing technique used is given by Hocking et al. (2001).

Typical meteor distributions will now be presented to compare the difference between the performances of the two systems. Figure $1 \mathrm{a}$ and $\mathrm{b}$ presents the average number of meteor echoes received per day by the radars over the course of a year. The data from Rothera are from February 2005 to April 2009. The data from Esrange are from October 1999 to April 2009. Both plots show the existence of an annual cycle, superimposed upon which brief episodes of higher meteor counts are found during meteor showers. Examples of meteor showers can be seen over Esrange in January (the Quadrantids shower) and December (the Geminids shower).

The highest meteor count rates, discounting showers, are found during the summer solstice (days 355 over Rothera and days 172 over Esrange). Over both sites the count rates minimise during spring. Daily meteor counts vary between $\sim 3000$ and 7000 over Rothera and between $\sim 2000$ and 5000 over Esrange. The yearly-averaged meteor count rate per day over Rothera is 4738 meteors, compared with that seen over Esrange which is 3465 meteors. The differences between the count rates recorded over Rothera and Esrange arises from differences in the levels of radio interference at the two sites, small differences in the performance of the radars and differences in the strengths of the visible sporadic meteor radiants. The annual cycle of count rates is a consequence of the visibility above the horizon of the astronomical sources of sporadic meteors (radiants) (e.g., Younger et al., 2009).

Figure $2 \mathrm{a}$ and $\mathrm{b}$ presents the normalised diurnal variation of meteor counts in local time for Rothera and Esrange, respectively. A clear diurnal cycle is apparent. The diurnal cycle over the two sites is almost identical. The highest meteor count rates occur in the early hours of the morning, at about 06:00 LT and the lowest count rates occur in the late afternoon at about 18:00 LT. The ratio of maximum to minimum count rates over both sites is about 2:1.

An annual cycle in the diurnal distribution of meteor count rates is also observed. Figure $3 \mathrm{a}$ and $\mathrm{b}$ present monthly normalised hourly meteor counts between 00:00 and 24:00 LT for Rothera and Esrange, respectively. Data from all years available are used and so the figures present composite years. Note that the Rothera year is shifted by six months to ease comparison with Esrange. The figure thus shows how the diurnal cycle in meteor count rates varies throughout the year. In particular, the hour of day at which the greatest meteor count rates occurs changes from $\sim 07: 00-08: 00 \mathrm{LT}$ in late spring, summer and early autumn (November-March over Rothera and April-September over Esrange) to earlier in the day in the remainder of the year e.g., 03:00-06:00 LT (from April to October over Rothera and October to March over

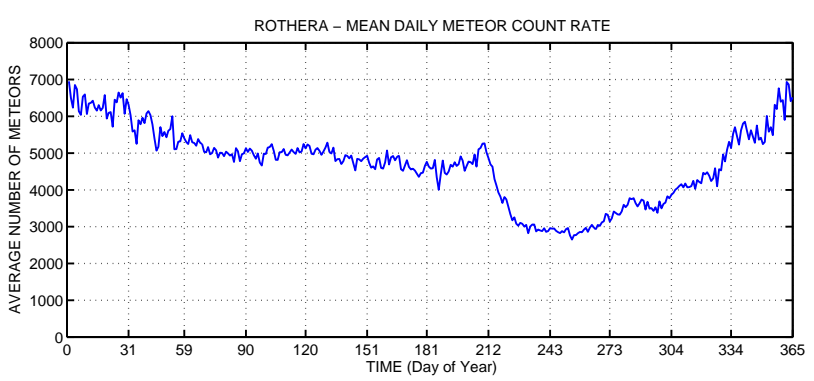

(a)

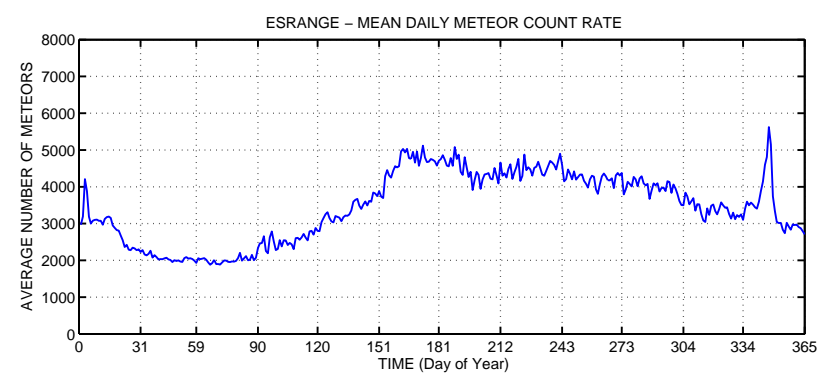

(b)

Fig. 1. Composite-year daily meteor counts for the (a) Rothera and (b) Esrange meteor wind radars (i.e., average number of meteors detected per day). The Rothera results have been averaged over about 4 years from 2005 to 2009 . The Esrange results over about 7 years from 1999 to 2009 .

Esrange). This behaviour is again a consequence of the visibility above the horizon of the astronomical sources of sporadic meteor radiants. A more detailed examination of these variations is presented in Younger et al. (2009).

The normalised distribution of meteor echoes with height over Rothera and Esrange is presented in Fig. 4a and b. All recorded meteors are used. The meteor counts over both sites peak at a height of $90 \mathrm{~km}$ and have very similar distributions. These distributions of meteor echoes determine the heights and times at which mesospheric winds can be calculated, since sufficient meteors must be present in a particular height-time interval to allow a robust determination of the winds. A minimum of 5 meteors were used for this determination. Generally, this meant that sufficient meteors were available to calculate winds even during the low-count-rate part of the day in the outermost height gates.

In routine calculation of mesospheric winds, the individual meteor echoes are sorted into six independent height gates covering the ranges $78-83,83-86,86-89,89-92,92-95$, and $95-100 \mathrm{~km}$. A least-squares fitting was then used to fit to the azimuth and horizontal component of the drift velocity to determine the zonal and meridional winds within a particular height gate. This fitting was performed for all meteors observed in each height gate using a two-hour window incremented through the data set in steps of one hour. 


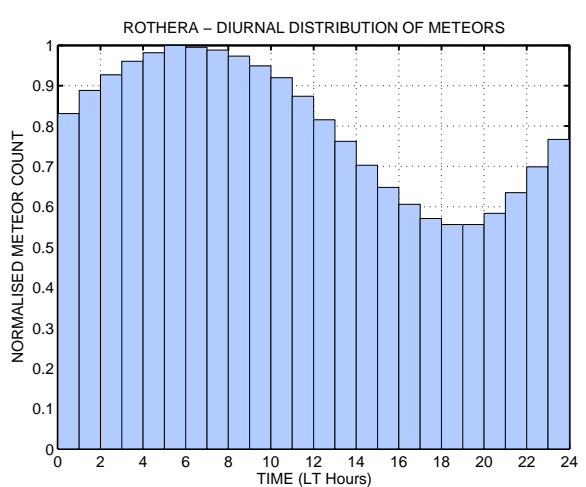

(a)

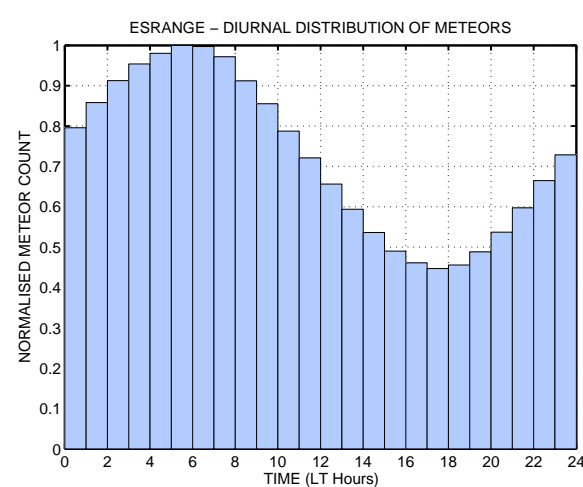

(b)

Fig. 2. Normalised diurnal variation in the meteor counts with respect to local time for the (a) Rothera meteor radar between 2005 and 2009 and (b) Esrange meteor radar between 1999 and 2009.

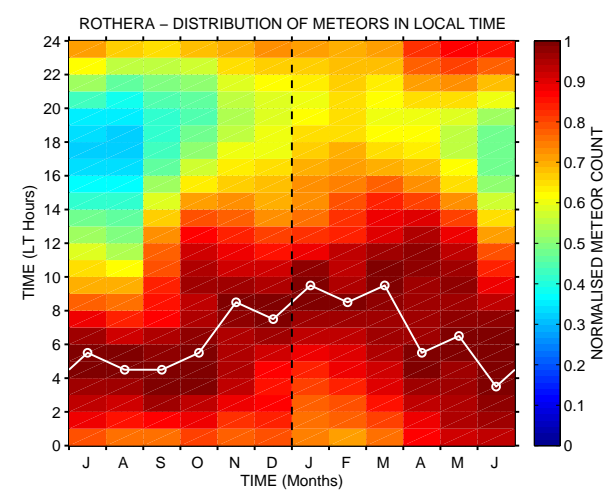

(a)

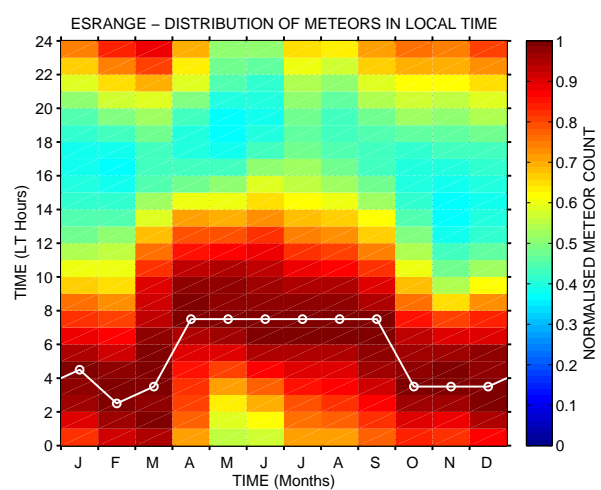

(b)

Fig. 3. Normalised diurnal variation in the meteor counts versus month with the peak hours of counts marked with the white line, for the (a) Rothera meteor radar between 2005 and 2009 and (b) Esrange meteor radar between 1999 and 2009.

For the available data, this method lead to $\sim 7.2 \%$ datagaps for the upper and lower most height gates for Rothera and $\sim 10.3 \%$ for Esrange. Errors in the resulting two-hour mean winds are typically only a few $\mathrm{ms}^{-1}$. Because of the uneven distribution of meteors with height, the height gates are assigned representative centres of $80.8,84.6,87.5,90.4,93.4$ and $97.1 \mathrm{~km}$, corresponding to the mean height recorded in each height gate, calculated using the Esrange data. The base data product is thus hourly spaced zonal and meridional winds in six height gates over each site.

\section{Results}

\subsection{Observations of mean winds over Rothera and Esrange}

To investigate the behaviour of the background winds over the two sites, monthly-mean winds were calculated for each height gate, using individual months of data. The monthlymean winds for each year measured over Rothera between February 2005 and April 2009 are presented in Figs. 5ae and $6 \mathrm{a}-\mathrm{e}$ for zonal and meridional winds, respectively. In these figures the zero-wind line is marked with a heavy dashed contour. Figures $5 \mathrm{f}$ and $6 \mathrm{f}$ present the standard deviations of the monthly-mean winds measured each year, providing a simple quantification of inter-annual variability. The reader should bear in mind that the use of monthly-mean 


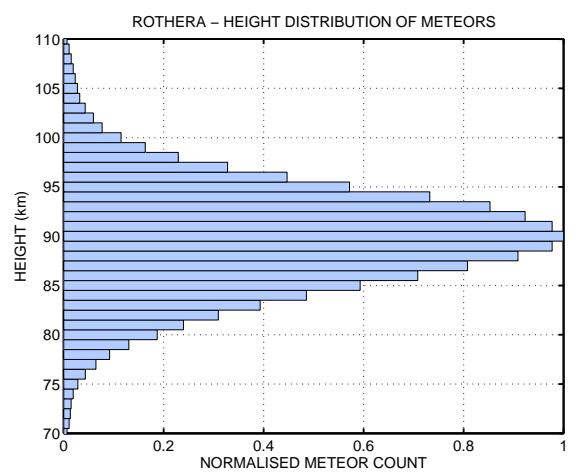

(a)

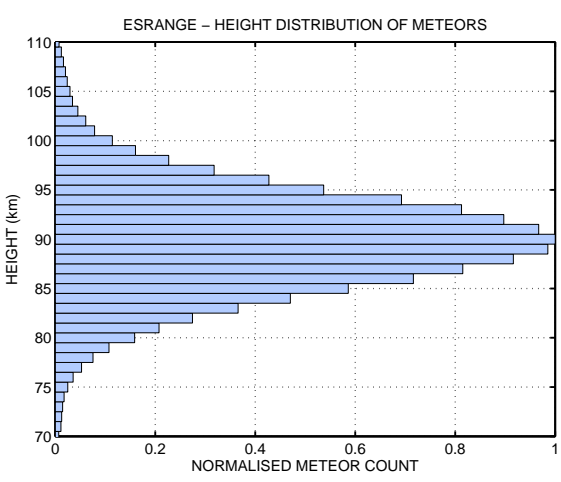

(b)

Fig. 4. Normalised variation of meteor counts with height for the (a) Rothera meteor radar between 2005 and 2009 and (b) Esrange meteor radar between 1999 and 2009.

winds means that shorter-period fluctuations may be overlooked. Note that in this study, for Arctic results winter will refer to December-February, spring to March-May, summer to June-August and autumn to September-November. For the Antarctic, this is shifted by 6 months, so that winter refers to June-August, spring to September-November, summer to December-February and autumn to March-May.

In the observed zonal winds over Rothera, the seasonal pattern is seen to repeat in general form from year to year. The most conspicuous features apparent are the strong summertime wind shears in December, January and February. This shear is the top of the westward summertime mesospheric jet. The strongest westward winds are observed in early summer (November-December) where the winds become as strong as $-50 \mathrm{~m} \mathrm{~s}^{-1}$ in 2007 at heights near $80 \mathrm{~km}$. At greater heights and as summer progresses the winds become increasingly eastward ultimately reaching flows as strong as $\sim 30 \mathrm{~m} \mathrm{~s}^{-1}$ at heights near $97 \mathrm{~km}$ in late summer (February-March). In contrast, the wintertime winds are generally more variable from year to year but are largely eastward at all heights. Maximum values of $\sim 20 \mathrm{~m} \mathrm{~s}^{-1}$ are frequently seen in August over Rothera. The zonal wind standard deviations of Fig. 5f reveal that the greatest variability of the monthly-mean zonal winds occurs at the end of spring during the build up to the strongest westward winds.

In the meridional winds observed over Rothera, a seasonal pattern that repeats from year-to-year, is also evident, at least in summer. The most conspicuous feature is a period of equatorward flow during the summer, which generally occurs over all heights observed and reaches velocities of up to $14 \mathrm{~m} \mathrm{~s}^{-1}$. However, the meridional winds in summer vary significantly from year-to-year. There is a generally tendency for the flow to be equatorward, particularly so in the upper heights observed. However, episodes of poleward flow do occur during the winter, especially at the lower heights observed. The greatest variability during winter occurs at the upper heights. For example meridional winds reach more than $14 \mathrm{~m} \mathrm{~s}^{-1}$ equatorward above $94 \mathrm{~km}$ in July 2005, whereas at the same height and time in 2006 the winds are actually poleward and reach $-6 \mathrm{~m} \mathrm{~s}^{-1}$. In spring and autumn, the meridional flow is often near zero with a tendency for poleward in autumn and equatorward in spring. The variability is revealed in the meridional winds standard deviations of Fig. 6f, which suggest greatest variability occurs in the lower heights during summer (December) and the upper heights during the winter (July).

A similar analysis for Esrange is presented in Figs. 7a-k and $8 \mathrm{a}-\mathrm{k}$, for zonal and meridional winds, respectively. The data cover the interval of between October 1999 and April 2009. For both zonal and meridional winds, a generally similar pattern is observed, with an annually-repeating seasonal cycle which looks superficially similar to that seen in the zonal winds over Rothera. However, a number of significant differences are apparent, which will be discussed below. Figures 71 and 81 present the standard deviations of the monthly-mean zonal and meridional winds. These latter figures indicate that the greatest level of inter-annual variability occurs in late winter and spring over Esrange and particularly at heights below $\sim 88 \mathrm{~km}$. This high level of variability probably represents inter-annual differences arising from the mesospheric manifestation of stratospheric warmings.

For the zonal winds, a generally similar pattern to Rothera is observed, with an annually repeating seasonal cycle which looks superficially similar to that seen in the zonal winds over Rothera. Again, strong shears are observed in summer. The strongest westward winds are observed in summer (June-August) where the winds reach speeds of $\sim-30 \mathrm{~m} \mathrm{~s}^{-1}$ near $80 \mathrm{~km}$. At greater heights the winds become eastward, reaching flows as strong as $\sim 35 \mathrm{~m} \mathrm{~s}^{-1}$ at heights near $96 \mathrm{~km}$ in late summer (August). The wintertime winds are generally 


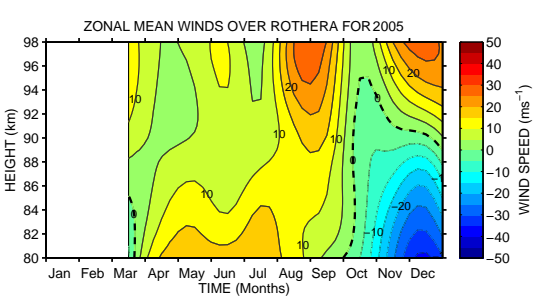

(a)

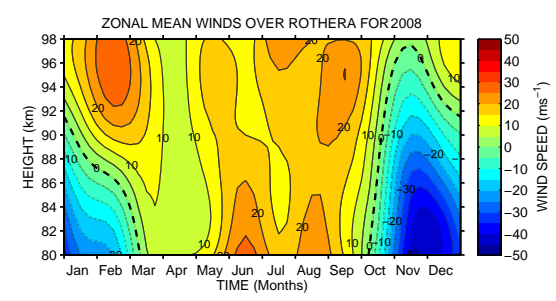

(d)

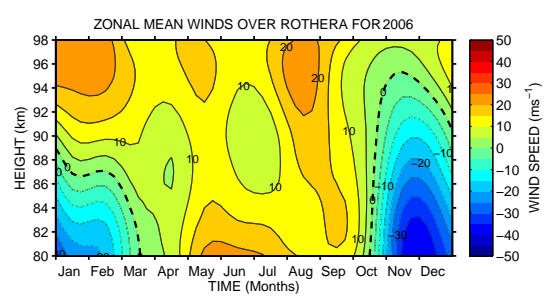

(b)

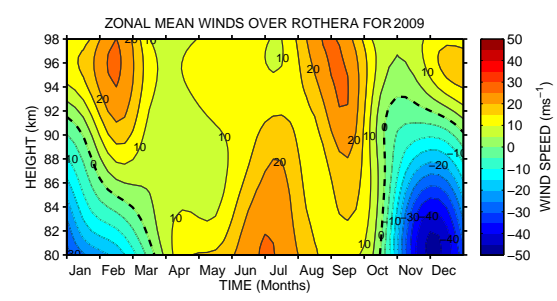

(e)

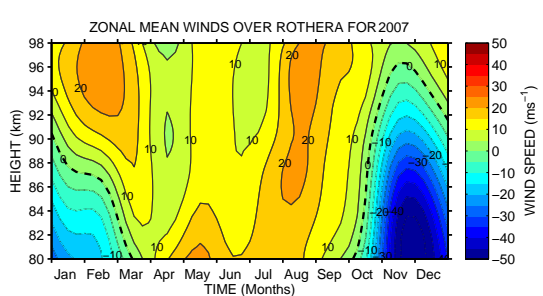

(c)

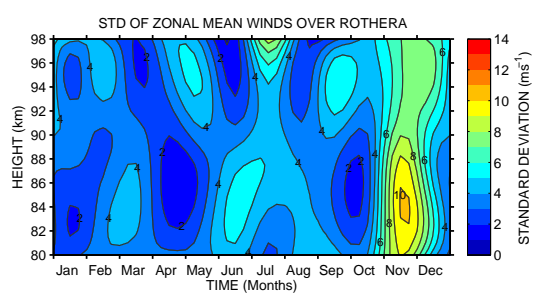

(f)

Fig. 5. (a-e) Monthly-mean zonal winds measured by the Rothera meteor radar for individual years between 2005 and 2009 . (f) The standard deviation of all years of monthly-mean zonal winds.

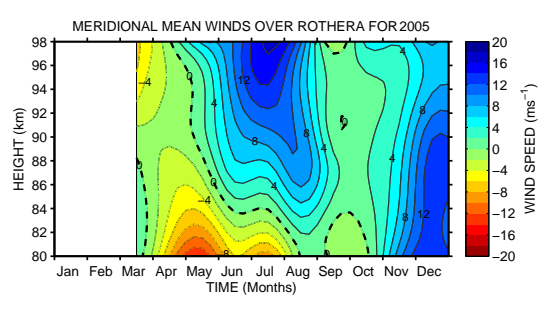

(a)

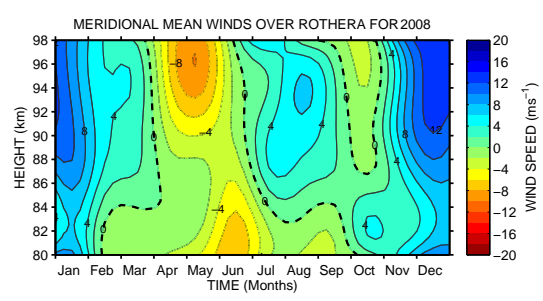

(d)

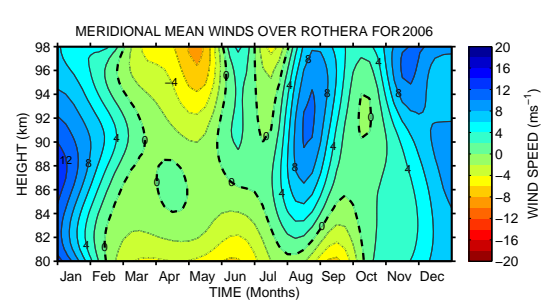

(b)

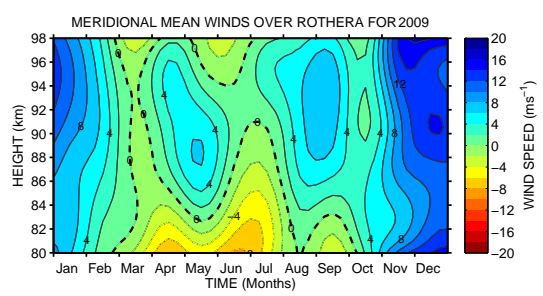

(e)

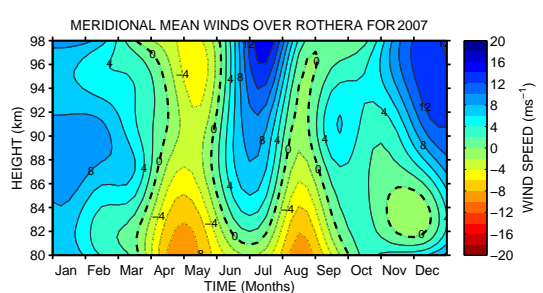

(c)

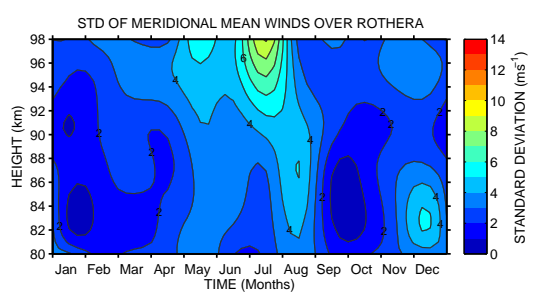

(f)

Fig. 6. (a-e) Monthly-mean meridional winds measured by the Rothera meteor radar for individual years between 2005 and 2009 . (f) The standard deviation of all years of monthly-mean meridional winds. 


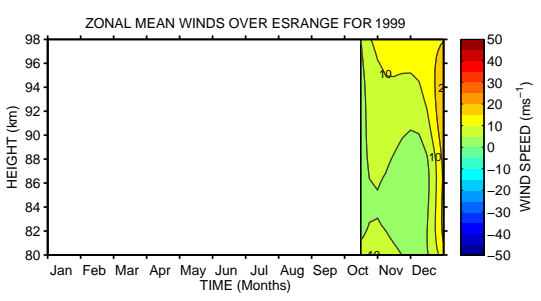

(a)

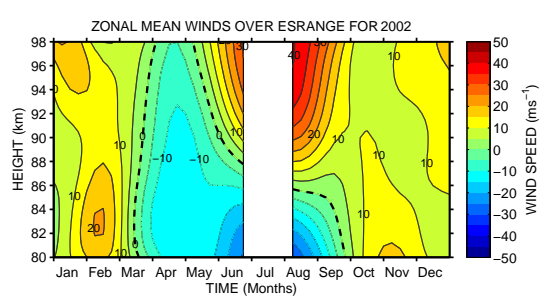

(d)

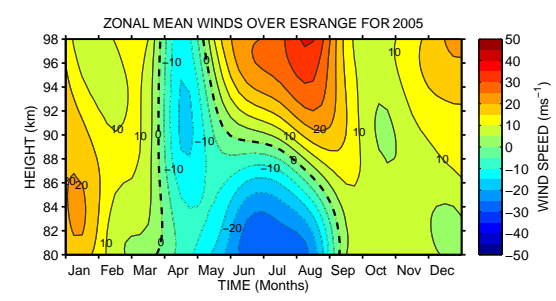

(g)

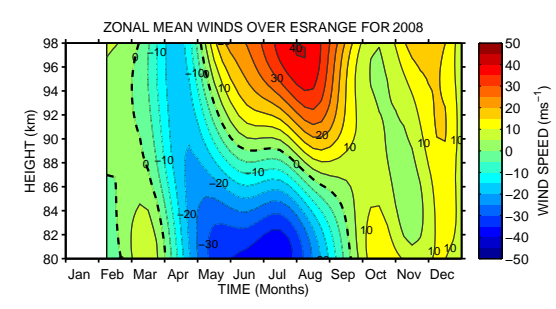

(j)

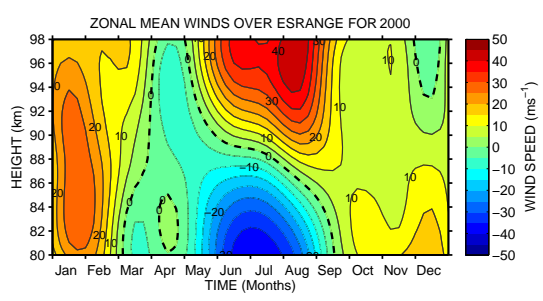

(b)

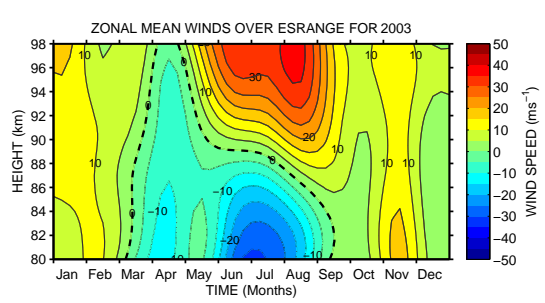

(e)

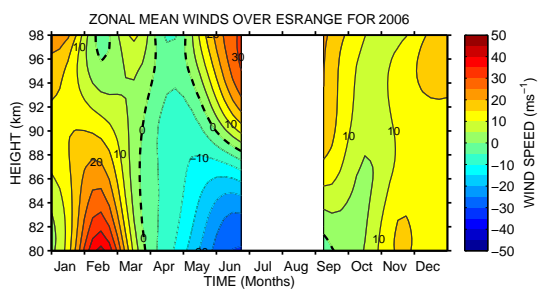

(h)

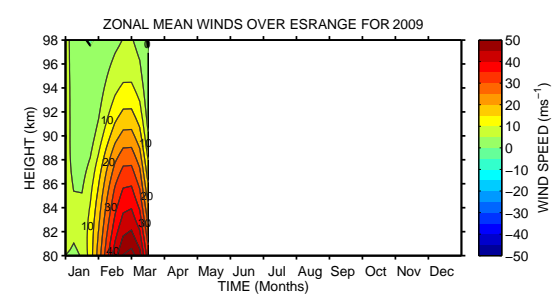

(k)

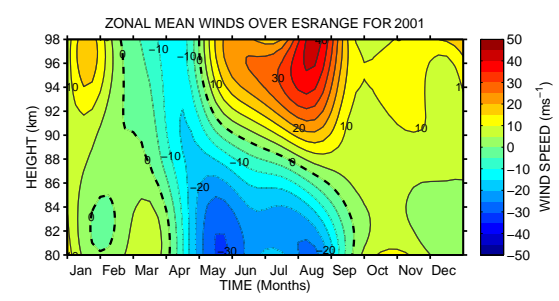

(c)

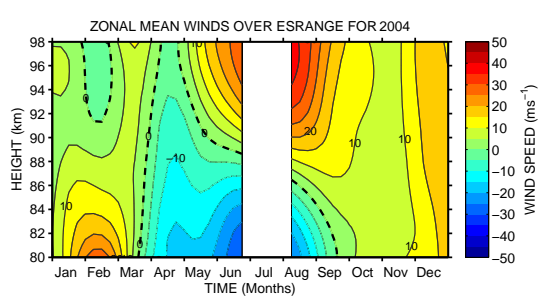

(f)

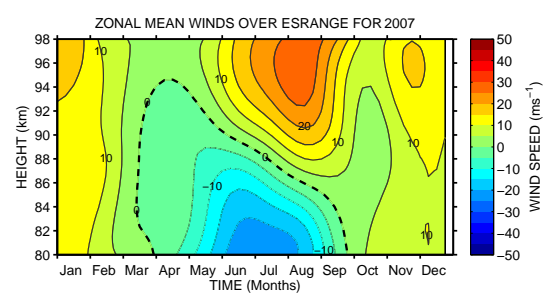

(i)

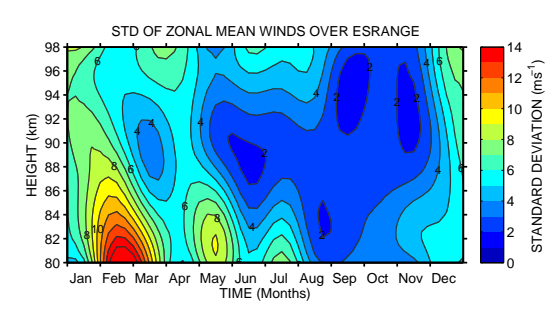

(1)

Fig. 7. (a-k) Monthly-mean zonal winds measured by the Esrange meteor radar for individual years between 1999 and 2009. (l) The standard deviation of all years of monthly-mean zonal winds. 
more variable from year to year but are largely eastward at all heights. Maximum values of $\sim 25 \mathrm{~m} \mathrm{~s}^{-1}$ are seen in JanuaryFebruary over Esrange.

In the meridional winds observations over Esrange, again a seasonal pattern is observed. The most striking feature is the clearly defined region of equatorward flow found during the summer months (May to August). This flow varies in shape and strength, but maximises at heights between about 84 and $90 \mathrm{~km}$ in all years observed with speeds of up to $16 \mathrm{~m} \mathrm{~s}^{-1}$. In late summer (July-August) the meridional winds reverse to give poleward flow above heights of about $94 \mathrm{~km}$ in all of the observed years. The standard deviations of Fig. 81 suggest that the equinox and wintertime flows are more variable. In some years, the winds are predominantly poleward, reaching speeds of up to $10 \mathrm{~m} \mathrm{~s}^{-1}$ (e.g., February 2001) and in contrast, in other years the winds are predominantly equatorward, reaching speeds of $-10 \mathrm{~m} \mathrm{~s}^{-1}$ (e.g., February 2003).

The focus of the present work is to determine the differences between the mean winds of the Antarctic and Arctic regions. We will therefore now turn our attention to a detailed comparisons of the monthly mean winds recorded over Rothera and Esrange.

\subsection{Similarities and differences in the mean winds over Rothera and Esrange}

To investigate systematic differences between the winds of the Antarctic and Arctic, composite-year monthly-mean climatologies were constructed by averaging the data from all the individual years. Figures 9 and 10 present these composite years. Figure 9 presents the zonal-mean winds. The data from Rothera have been displaced by 6 months to help make seasonal comparisons. These figures show the behaviour of the mean winds with the inter-annual variability to some extent smoothed out. A Student's $t$-test was employed to highlight the significance of the differences between the winds of the Arctic and Antarctic. Using a confidence limit of 95\%, a number of significant differences are apparent between the winds. These include:

1. The westward summertime wind over Rothera is significantly stronger than that over Esrange. Further, the strongest westward winds occur approximately one month earlier over Rothera than over Esrange. For example, the strongest westward flow of $\sim-40 \mathrm{~m} \mathrm{~s}^{-1}$ occurs over Rothera in November-December at the lowest heights, whereas the strongest westward winds over Esrange reach only $\sim-25 \mathrm{~m} \mathrm{~s}^{-1}$ in June-July, which is slightly later in the season. Because the reversal to westward winds occurs at approximately the same point in the season over Rothera and Esrange, this means that the rate of change of zonal winds with time is greater over Rothera, since the strongest westward winds occur less than 2 months after the wind reversal, where as over Esrange, the strongest winds occur more than 3 months after the reversal. Note that, in fact, the reversal to westward winds occurs slightly later in the season over Rothera than over Esrange, the differences generally amounting to less than 1 month (see Point 3 below). To illustrate this general point, if we consider the winds at a height of $80 \mathrm{~km}$, the accelerations required to produce the strongest westward winds from the point at which the winds reverse into the summer circulation are: $-24.6 \mathrm{~m} \mathrm{~s}^{-1}$ per month for Rothera and $-9.5 \mathrm{~m} \mathrm{~s}^{-1}$ per month for Esrange.

2. The eastward summertime flow at the upper heights over Rothera is significantly weaker than that over Esrange. For example, the strongest eastward flow of more than $25 \mathrm{~m} \mathrm{~s}^{-1}$ occurs at the upper heights in a three-month interval over Esrange (June to August), whereas the eastward winds over Rothera only reach $25 \mathrm{~m} \mathrm{~s}^{-1}$ briefly in February. Further, the strongest eastward flows over Rothera are significantly weaker than over Esrange. Specifically, the strongest monthly-mean winds over Rothera reach only $25 \mathrm{~m} \mathrm{~s}^{-1}$ where as over Esrange it reaches more than $35 \mathrm{~m} \mathrm{~s}^{-1}$.

3. The location of the zero-wind line shows that the summertime westward flow commences about one month later over Rothera than over Esrange (October over Rothera cf. late March over Esrange).

4. The zero wind line over Rothera does not reach higher than $\sim 95 \mathrm{~km}$ (which occurs in November). Examination of the individual years (Fig. 5a-e) shows that the winds never reverse to become westwards at the upper heights observed. In contrast, over Esrange the winds reverse to become westward at all heights in April/May. Examination of the individual years (Fig. 7a-k) shows that the winds reversed at all heights in eight of the nine years observed (2007 being the exception).

5. During autumn and winter, of the two polar regions, the composite-year winds generally agree to within about $5-10 \mathrm{~m} \mathrm{~s}^{-1}$. However, it is noticeable that in late winter/early spring, differences are apparent at heights above about $90 \mathrm{~km}$. In particular, in the Antarctic data in August-September the zonal winds exceed $20 \mathrm{~m} \mathrm{~s}^{-1}$, whereas, in February-March in the Arctic, they are generally only $5-10 \mathrm{~m} \mathrm{~s}^{-1}$. However, these differences were not found to be significant.

Figure 10a and $\mathrm{b}$ presents a similar analysis for the meridional winds. During spring and late winter, the meridional winds are not significantly different. However, differences are apparent throughout the rest of the year, even though amplitudes are not as large as in the zonal case. The features include: 


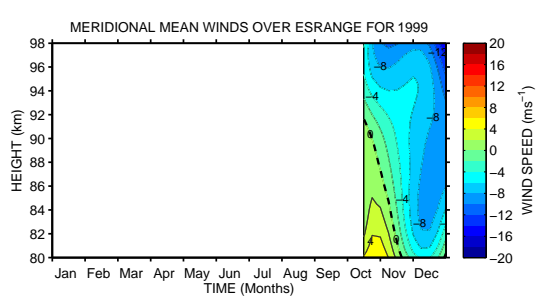

(a)

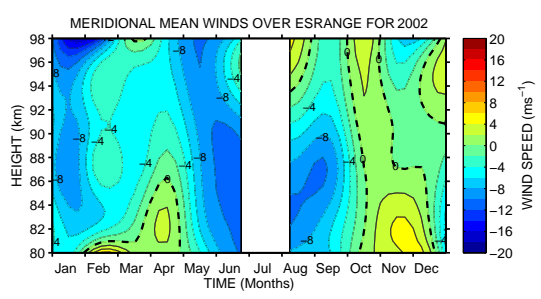

(d)

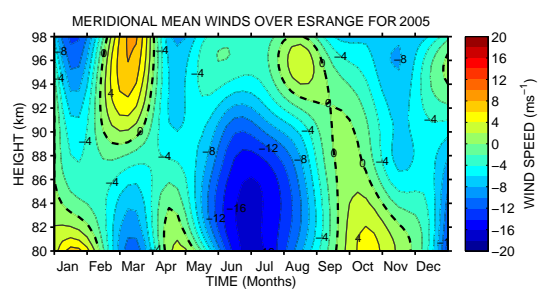

(g)

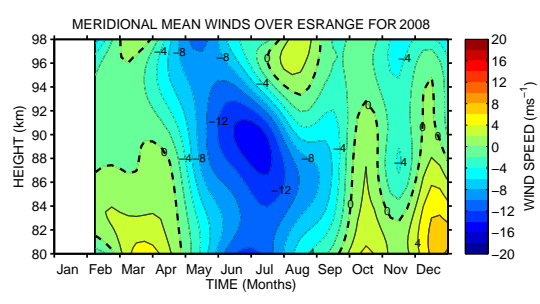

(j)

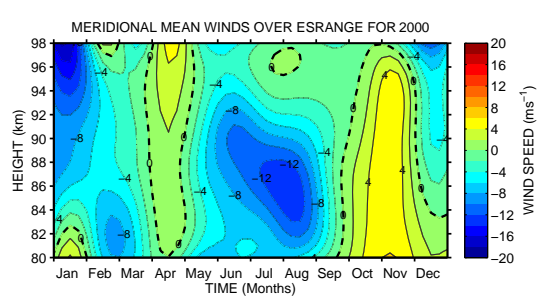

(b)

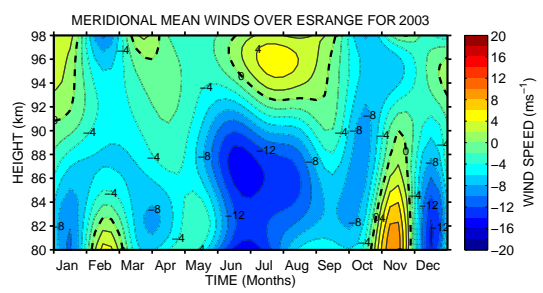

(e)

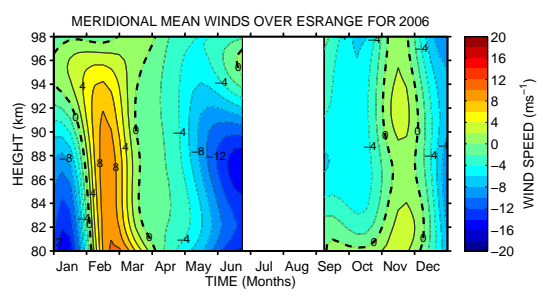

(h)

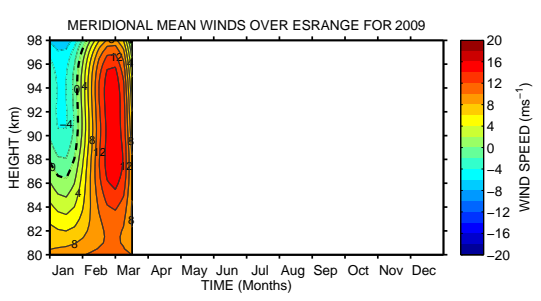

(k)

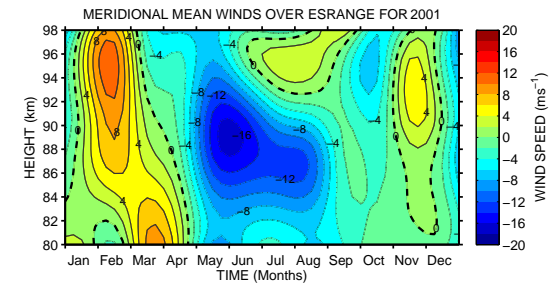

(c)

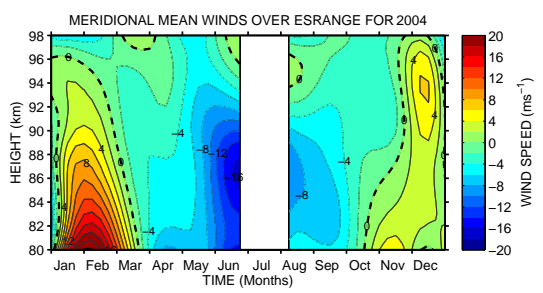

(f)

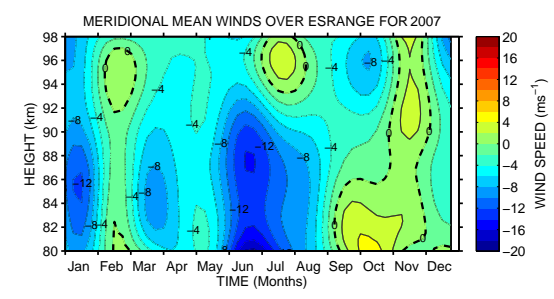

(i)

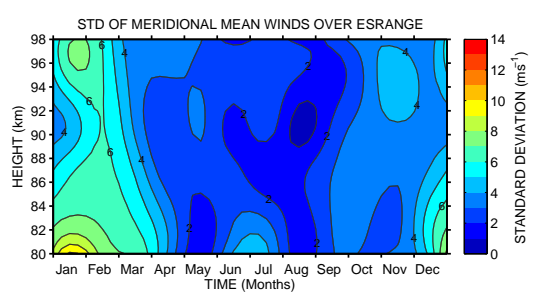

(1)

Fig. 8. (a-k) Monthly-mean meridional winds measured by the Esrange meteor radar for individual years between 1999 and 2009. (l) The standard deviation of all years of monthly-mean meridional winds. 
1. Throughout most of the year the flow is equatorward and the strongest equatorward flow occurs during summer. Episodes of poleward flow occur in autumn and winter. However, there is a slight tendency for the strongest poleward flows to persist for longer after the summer solstice in the Arctic than the Antarctic.

2. Over Rothera this summertime flow is present over the entire height range observed. The greatest flow speeds exceed $10 \mathrm{~m} \mathrm{~s}^{-1}$ in December. In contrast, over Esrange the meridional flow in summer is more localised with a slightly stronger equatorward flow maximising at heights near $87 \mathrm{~km}$ (wind speeds exceed $12 \mathrm{~m} \mathrm{~s}^{-1}$ ). However, above this height, the winds actually reverse to become poleward at heights above $94 \mathrm{~km}$ during July and August. Examination of Fig. 8a-k, shows this region of poleward flow occurs over Esrange in each of the 9 summers observed, but no corresponding feature was seen over Rothera in any of the 5 summers observed.

3. The standard deviation plot of Fig. 6f shows that the greatest variability of the meridional winds over Rothera occurs during winter (June-August). Similarly the standard deviation plot of Fig. 81 shows that the greatest variability over Esrange also occurs during winter (December to February). In fact, examination of Fig. 8a-k reveals that the monthly mean meridional winds can blow either poleward or equatorward in different years. For example, strong wintertime poleward flows are evident in 2001, 2004, 2006 and 2009. This year-to-year difference probably represents the behaviour of stationary planetary waves (see Sect. 4).

The meridional summertime jets over both sites occur simultaneously with the strong shear in the zonal wind. The maximum equatorward meridional winds occur on or just below the zero-wind line in the zonal winds.

\subsection{Comparison of mean winds with the UARS reference atmosphere project}

The radar observations will now be compared with the URAP (UARS Reference Atmosphere Project) empirical model. URAP uses measurements from UARS (Upper Atmosphere Research Satellite). The data comprises zonal-mean winds derived from HRDI (High Resolution Doppler Imager) measurements in the middle atmosphere made from January 1992 to December 1995, supplemented by data from the UK Met Office Stratospheric data assimilation system and other sources (e.g., Swinbank and Ortland, 2003). Note that the HRDI instrument measures to latitudes of $72^{\circ}$, with the region between $40^{\circ} \mathrm{S}$ and $40^{\circ} \mathrm{N}$ being the highest sampled. This model contains the zonal mean zonal winds only.

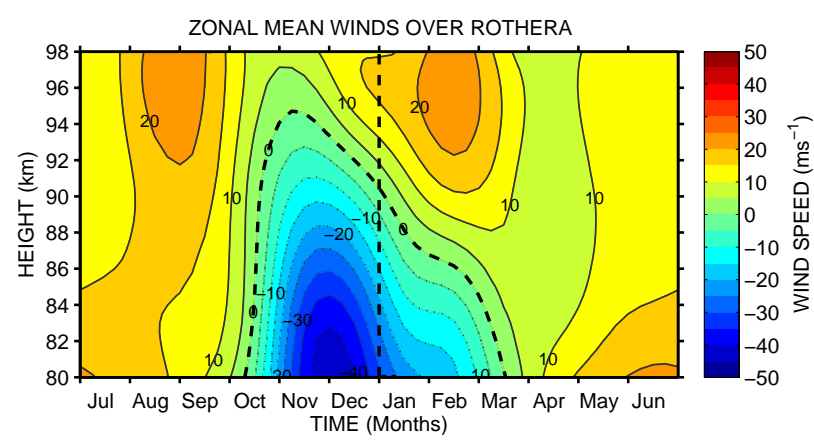

(a)

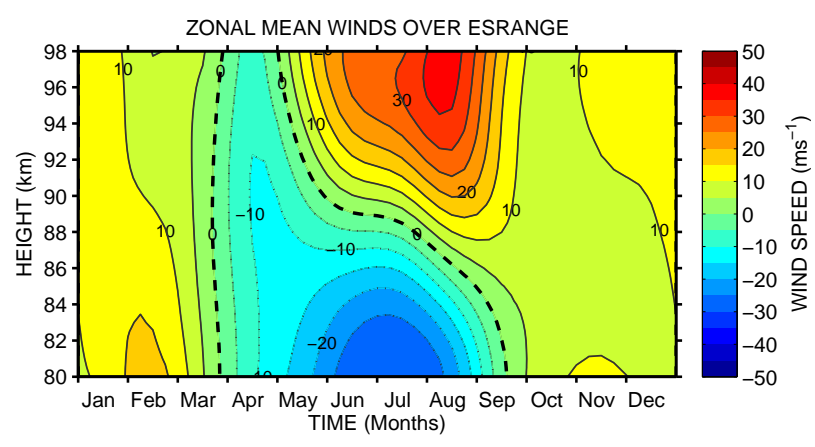

(b)

Fig. 9. Monthly-mean zonal winds measured by (a) the Rothera meteor radar between 2005 and 2009 and (b) the Esrange meteor radar between 1999 and 2009. Note that (a) has been shifted in time by six months to aid comparisons (i.e., summers are in the centre of both (a and $b)$ ).

We will now compare our observations and URAP at the latitude of Rothera $\left(68^{\circ} \mathrm{S}\right)$ and Esrange $\left(68^{\circ} \mathrm{N}\right)$. Figure 11a and $b$ presents the monthly-mean zonal winds from URAP at $68^{\circ} \mathrm{S}$ and $68^{\circ} \mathrm{N}$, respectively. The figures are plotted such that the summers are in the centre.

Firstly, comparing these winds with those recorded by the Rothera meteor radar (Fig. 9a), it can be seen that URAP represents the summertime winds remarkably well. One difference which is apparent, however, is that the time in spring at which the zonal winds reverse from eastward to westward, is systematically different between the radar winds and URAP. In particular the reversal in URAP generally occurs in late September or early October at heights up to $90 \mathrm{~km}$, whereas the radar observations, show the reversal to occur approximately 2 weeks later, i.e. in mid to late October. The differences noted above are evident in each of the 5 years of radar data.

In contrast to the good agreement in summer, the eastward wintertime winds in URAP are significantly stronger than those observed over Rothera, often exceeding $30 \mathrm{~m} \mathrm{~s}^{-1}$, whereas over Rothera the winds are generally in the 10$15 \mathrm{~m} \mathrm{~s}^{-1}$ range. Examination of the individual years of zonal winds over Rothera suggests that there are regular short- 


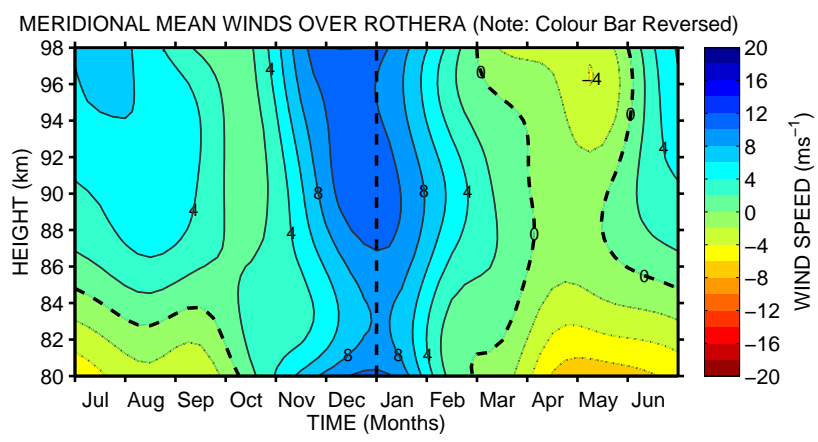

(a)

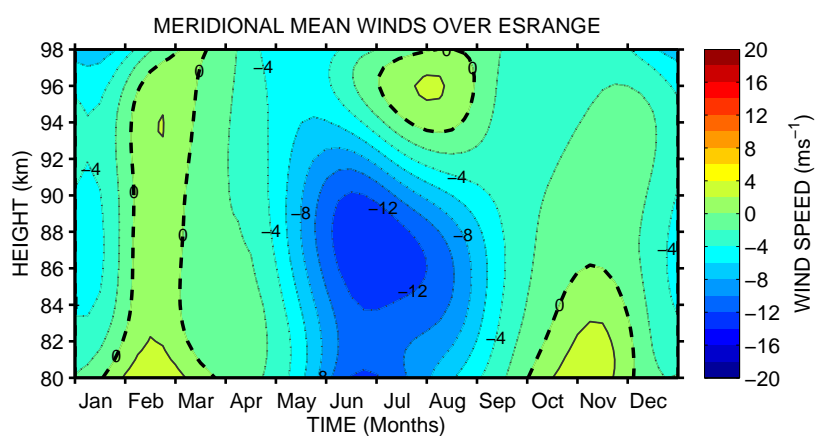

(b)

Fig. 10. Monthly-mean meridional winds measured by (a) the Rothera meteor radar between 2005 and 2009 and (b) the Esrange meteor radar between 1999 and 2009. Note that (a) has been shifted in time by six months and the colour bar has been reversed to aid comparisons (i.e., the blue side of the scale indicates equatorward flow and the red side indicates poleward).

lived episodes where the wintertime zonal winds do exceed $20 \mathrm{~m} \mathrm{~s}^{-1}$. However, the strong and persistent westward winds of URAP are simply not observed over Rothera. The differences between our observations and URAP during the winter are generally in the order of $10-20 \mathrm{~m} \mathrm{~s}^{-1}$.

Secondly, we will now compare the observations and URAP at the latitude of Esrange $\left(68^{\circ} \mathrm{N}\right)$. Figure $11 \mathrm{~b}$ presents the monthly mean zonal winds from URAP at $68^{\circ} \mathrm{N}$. Comparing these with the observations over Esrange (Fig. 9b), It can be seen that the agreement is generally quite good. However, there are again a number of significant differences. In contrast to the situation in the Antarctic, over Esrange the wintertime winds agree quite well and it is the summers which disagree. In particular, in April/May the winds reverse to be westwards at all heights over Esrange, whereas in URAP, the winds above $\sim 92 \mathrm{~km}$ are always eastwards and never reverse. In fact, the individual years of radar observations presented in Fig. $7 \mathrm{a}-\mathrm{k}$, show this to be the case in 8 of the 9 early summers observed. Further, in the radar observations the zonal winds over Esrange reverse almost simultaneously at all heights in late March to the summertime westward flow. The height of the zero-wind line associated

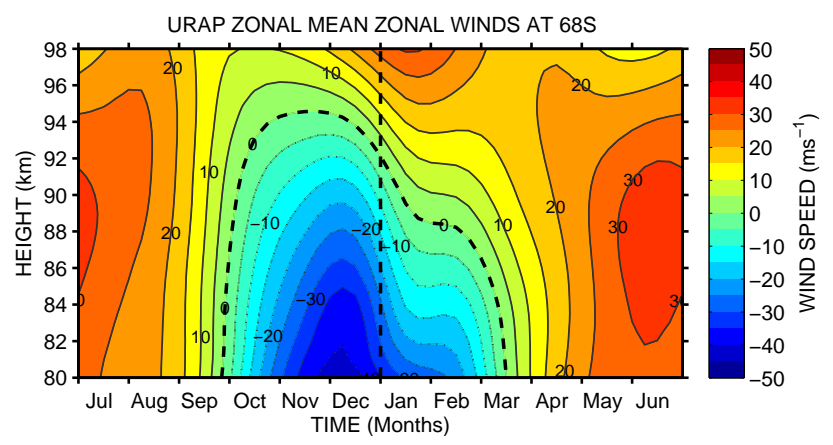

(a)

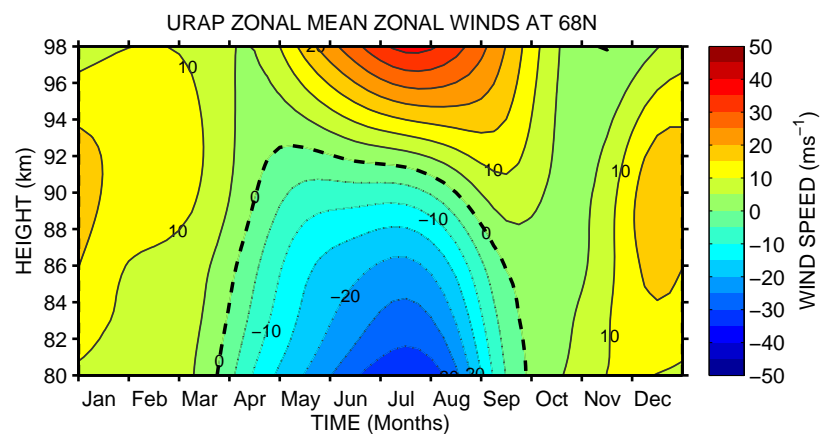

(b)

Fig. 11. The longitudinally average monthly-mean zonal winds from the URAP empirical model for an average year (a) for the Southern Hemisphere $\left(68^{\circ} \mathrm{S}\right)$ and (b) for the Northern Hemisphere $\left(68^{\circ} \mathrm{N}\right)$. Note that $(\mathrm{a})$ has been shifted in time by six months to aid comparisons.

with the second summertime reversal from westward back to eastward winds is systematically lower by about $2 \mathrm{~km}$ in the observations over Esrange. A consequence of this is that, since the magnitude of the summertime wind shear is about the same in URAP and our radar observations, the eastward winds observed in the upper heights are stronger over Esrange than in URAP by about $10 \mathrm{~m} \mathrm{~s}^{-1}$. In contrast to the Antarctic, the wintertime winds of URAP in the Arctic are of generally similar magnitude to those observed over Esrange; with differences being at most $5 \mathrm{~m} \mathrm{~s}^{-1}$.

The strong vertical structure of the zonal winds in summer allows an examination of the systematic differences between URAP and the radar data. The best agreement over Rothera (measured by minimising differences) occurs when the URAP winds are assigned to a height $1.7 \mathrm{~km}$ lower than in the URAP climatology (or equivalently the Rothera winds are assigned to a height $1.7 \mathrm{~km}$ higher). Similarly, the best agreement over Esrange occurs when the URAP winds are assigned to a height $1.2 \mathrm{~km}$ lower than in the URAP climatology (or equivalently the Esrange winds are assigned to a height $1.2 \mathrm{~km}$ higher). This might indicate a systematic error in one or both of the data sets. However, it should be borne in mind, that the years of observation are different for 
the satellite and radar data sets and that the URAP winds are zonal averages rather than the local measurements of the radars.

In summary, the summertime winds observed in the Antarctic agree very well with those of URAP, however, there are significant differences in winter with predicted winds sometime being twice as large as those observed. The springtime reversal is also $\sim 2$ weeks later in the observations than the model. In the Arctic, it is the wintertime winds which agree quite well with differences being at most $5 \mathrm{~m} \mathrm{~s}^{-1}$ and the summers which disagree. The springtime reversal is observed at all heights over Esrange, but not above $\sim 92 \mathrm{~km}$ in the model.

\subsection{Comparison of mean winds with the HWM-07 model}

The second model against which we will compare our observations is the provisional HWM-07 horizontal wind model (Drob et al., 2008). This model succeeds the earlier HWM93 model of Hedin et al. (1996). This latest version of HWM is based on the previous version with the addition of an extensive set of new measurements from ground-based and spacebased wind instruments. It contains both zonal and meridional components.

Firstly we will consider the zonal winds of HWM-07 which are presented in Fig. 12a and b, for Antarctic and Arctic latitudes, respectively. The HWM-07 winds capture some of the character of the meteor radar observations in summer in both the Antarctic and Arctic (Fig. 9a and b). However, significant differences are apparent. In particular, in the Antarctic the spring reversal of the zonal winds from eastward to westward occurs about one month earlier in HWM-07, than observed, at heights below about $90 \mathrm{~km}$. The summertime westward winds in HWM-07 are slightly weaker than those observed by $\sim 10 \mathrm{~m} \mathrm{~s}^{-1}$ and the summertime eastward winds are slightly stronger than those observed by more than $10 \mathrm{~m} \mathrm{~s}^{-1}$. In the other seasons, the observed winds and those of HWM-07 are generally in the range 10$20 \mathrm{~m} \mathrm{~s}^{-1}$.

In contrast, the Arctic observations and HWM-07 winds (Figs. 9b and 12b) reveal striking differences. The summertime westward winds of HWM-07 are significantly weaker than observed. Further, the observed reversal in spring to westward flow which occurs at all heights during March is missing from HWM-07, where the winds remain eastwards above $\sim 85 \mathrm{~km}$. The summertime eastward winds in HWM07 are significantly stronger than those observed. The observations show the summertime eastward winds increasing in strength at all heights until the end of August when the winds abruptly decrease to values near $10 \mathrm{~m} \mathrm{~s}^{-1}$. At the same time, the HWM-07 winds remain strong at the upper heights. In autumn and winter there is generally very poor agreement between the observation and HWM-07. In particular, the

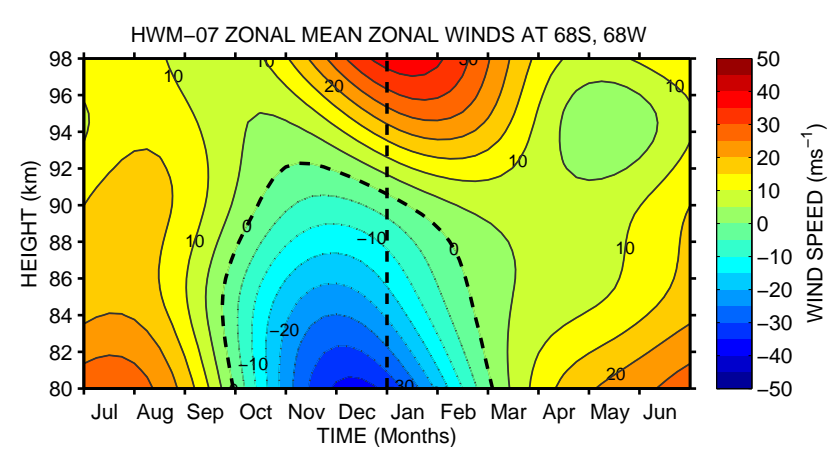

(a)

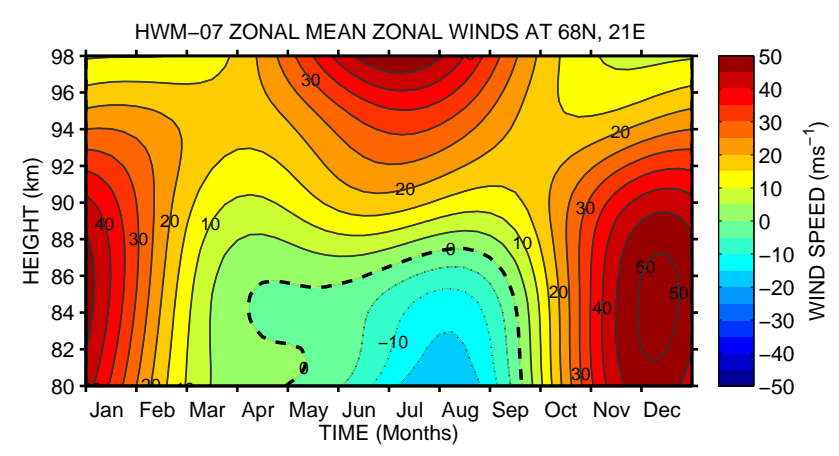

(b)

Fig. 12. Monthly-mean zonal winds from the HWM-07 empirical model for an average year (a) for the Southern Hemisphere $\left(68^{\circ} \mathrm{S}\right)$ and (b) for the Northern Hemisphere $\left(68^{\circ} \mathrm{N}\right)$. Note that (a) has been shifted in time by six months to aid comparisons.

observed winds are generally in the range $5-15 \mathrm{~m} \mathrm{~s}^{-1}$ at all heights, whereas the HWM-07 winds reach values exceeding $50 \mathrm{~m} \mathrm{~s}^{-1}$ below $90 \mathrm{~km}$.

Secondly, we will consider the meridional winds of HWM-07 which are presented in Fig. 13a and b for Antarctic and Arctic latitudes, respectively. In comparison to the meteor-radar observations of Fig. 10a and b, it can be seen that there are significant differences. In the case of the Antarctic, the observations show poleward winds throughout the year except in autumn and the lowest heights in winter. In contrast the HWM-07 winds are poleward except at the upper heights in summer and at the lower heights in winter. The magnitude of the poleward flows in HWM-07 is very much stronger than the poleward flows observed. For example, the observed winds reach only $-4 \mathrm{~m} \mathrm{~s}^{-1}$ in the upper heights in May, whereas the HWM-07 winds reach $-16 \mathrm{~m} \mathrm{~s}^{-1}$ at the same height and time. The strongly equatorward flows of HWM-07 are not evident in the observations at all. Further, the deep region of equatorward flow occurring in summer in the observations occurs only in upper heights of HWM-07 and the winds below $\sim 88 \mathrm{~km}$ are strongly poleward.

In the Arctic, large differences are also apparent. In particular, in spring, autumn and winter, HWM-07 includes regions of strong poleward flow, with speeds sometimes 
exceeding $12 \mathrm{~m} \mathrm{~s}^{-1}$. In contrast, the observations from Esrange reveal predominantly weak equatorward flow in these seasons. There is a region of poleward flow of $\sim 2 \mathrm{~m} \mathrm{~s}^{-1}$ in late winter over Esrange (February-March), but the corresponding flow in HWM-07 is significantly stronger with speeds greater than $8 \mathrm{~m} \mathrm{~s}^{-1}$ at heights below $88 \mathrm{~km}$. The distinctive region of equatorward flow observed to peak in June-July at heights of $\sim 86 \mathrm{~km}$ is also evident in HWM07; although in the model peak wind speed occur about one month earlier than observed. In both cases the equatorward wind speeds maximise at $\sim 12 \mathrm{~m} \mathrm{~s}^{-1}$.

In summary, zonal HWM-07 winds capture some of the features observed in summer of both regions. However, significant differences are apparent. In the Antarctic, model summertime westward winds are slightly weaker than observed and eastward winds are slightly stronger. Below $\sim 90 \mathrm{~km}$ the spring reversal occurs $\sim 1$ month earlier in HWM-07. In the other seasons the amplitudes are in a similar range. In the Arctic, the differences are more striking. Model summertime westward winds are much weaker than observed and eastward winds are stronger. The spring reversal is observed to occur at all heights, but is missing in HWM-07. Also the autumn and winter agreement is generally very poor. The meridional winds of HWM-07 do not agree well with the observations. Antarctic observations show equatorward winds throughout most of the year, when the HWM-07 shows generally poleward winds. At times when poleward flow is observed, it is much stronger in the model. In the Arctic from autumn to spring the HWM-07 has regions of strong poleward flow, where the observations show weak equatorward flow. The equatorward jet seen during summer is evident in both observations and the model, with similar amplitudes, however, the model peaks about one month earlier.

\section{Discussion}

In this section we will consider our measurements of the winds of the Antarctic and Arctic MLT and consider how they relate to those reported in other studies and with the URAP and HWM-07 empirical models. We will then specifically consider our results in the context of those studies attempting to identify inter-hemispheric differences. There are a useful number of studies that report the winds of the Arctic MLT, a somewhat smaller number that report the winds in the Antarctic MLT and very few that compare the winds of both polar regions using measurements made by essentiallyidentical instruments.

Studies of mean winds in the Antarctic MLT include those of Portnyagin et al. (1992, 1993, 2006), Vincent (1994), Dowdy et al. (2001, 2007a), Kishore et al. (2003), Hibbins et al. (2005), Merzlyakov et al. (2009). Here, we will not consider further the studies of Portnyagin et al. (1992), Merzlyakov et al. (2009) because they used meteor radars without height-finding capability and so reported winds that are

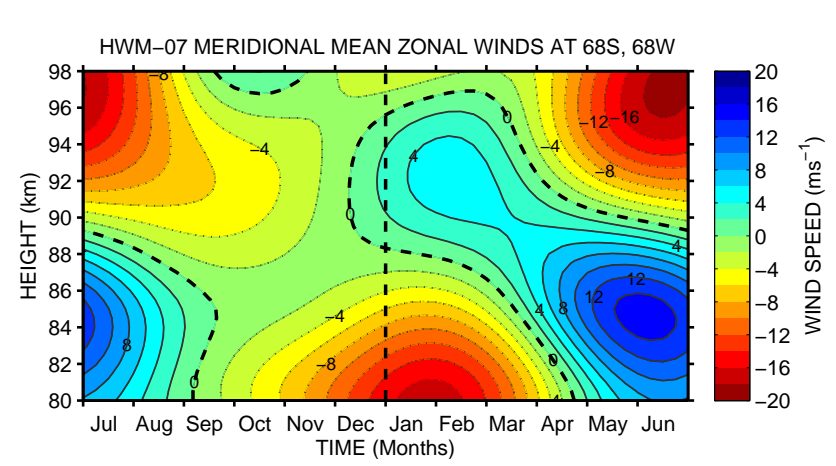

(a)

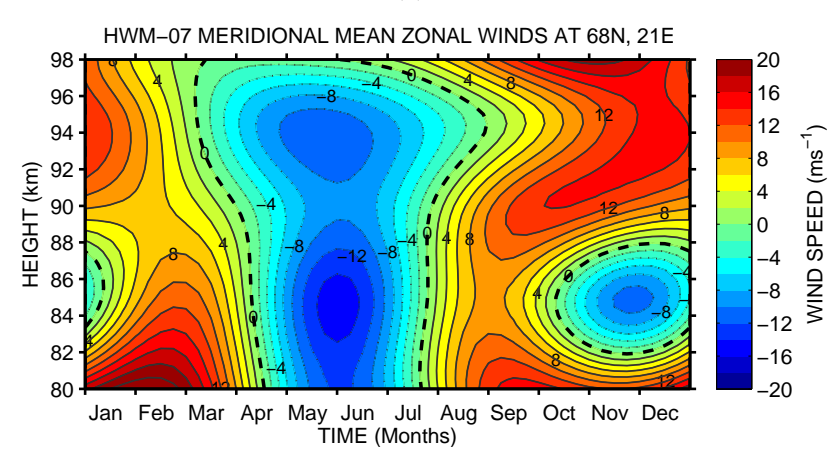

(b)

Fig. 13. Monthly-mean meridional winds from the HWM-07 empirical model for an average year (a) for the location of Rothera in the Southern Hemisphere $\left(68^{\circ} \mathrm{S}, 68^{\circ} \mathrm{W}\right)$ and (b) for the location of Esrange in the Northern Hemisphere $\left(68^{\circ} \mathrm{N}, 21^{\circ} \mathrm{E}\right)$. Note that (a) has been shifted in time by six months and the colour bar has been reversed to aid comparisons.

averages across the meteor region, rather than revealing the vertical structure of the winds.

Portnyagin et al. (1993, 2006), Vincent (1994), Dowdy et al. (2001, 2007a), Kishore et al. (2003), Hibbins et al. (2005) used selections of MF and Meteor radars at: Syowa $\left(69^{\circ} \mathrm{S}\right.$, $\left.40^{\circ} \mathrm{E}-\mathrm{MF}\right)$, Molodezhnaya ( $\left.68^{\circ} \mathrm{S}, 45^{\circ} \mathrm{E}-\mathrm{MWR}\right)$, Mawson $\left(67^{\circ} \mathrm{S}, 63^{\circ} \mathrm{E}-\mathrm{MF}\right)$, Davis $\left(69^{\circ} \mathrm{S}, 78^{\circ} \mathrm{E}-\mathrm{MF}\right)$, Scott Base $\left(78^{\circ} \mathrm{S}, 167^{\circ} \mathrm{E}-\mathrm{MF}\right)$, MaMurdo $\left(78^{\circ} \mathrm{S}, 166^{\circ} \mathrm{E}-\mathrm{MF}\right)$ and Rothera $\left(68^{\circ} \mathrm{S}, 292^{\circ} \mathrm{E}-\mathrm{MF}\right)$ to measure zonal and meridional winds in the Antarctic MLT region. In general, the seasonal pattern of winds described in Sect. 3.1 agrees well with those reported in the above studies. However, there are a number of significant differences. In particular, in the zonal winds, the strong wind shear evident over Rothera in summer that extends from $80-98 \mathrm{~km}$ is not observed above $\sim 92 \mathrm{~km}$ in any of the above results. For example, over Rothera, the summertime zonal winds reach speeds of up to $25 \mathrm{~m} \mathrm{~s}^{-1}$ in February at a height of about $97 \mathrm{~km}$ (Fig. 9a). In contrast, the zonal winds at the same height and time in the MF radar studies are generally in the range $5-10 \mathrm{~m} \mathrm{~s}^{-1}$. These differences probably do not result from real differences in 
the zonal winds over different sites, but rather appear to be typical of differences reported when meteor- and MF-radar measurements are compared.

These differences have been characterised by, e.g., Hocking and Thyaparan (1997), Manson et al. (2004). In general at heights above about $85-90 \mathrm{~km}$ MF radars record significantly weaker winds than meteor radars. Engler et al. (2008) estimated the winds measured by MF radar in the upper mesosphere to be too small by anywhere between 20 40\%. Similar results have been found by, e.g., Stubbs (1973), Cervera and Reid (1995), Hocking and Thyaparan (1997), Manson et al. (2004), Jacobi et al. (2009). The exact cause of these differences remains uncertain. The possibility of discrepancies highlight the importance of the meteor radar technique in measuring MLT winds above $85-90 \mathrm{~km}$.

Hibbins et al. (2005) used a combination of MF radar, falling sphere, radiosonde and model data to build up a climatology of zonal mean winds between 0 and $100 \mathrm{~km}$ above Rothera $\left(67^{\circ} \mathrm{S}, 68^{\circ} \mathrm{W}\right)$. The MF radar is located at the same site as the MWR used here. In fact, the antennas of the MWR are actually located within those of the MF radar, making these radars the most co-located MF/MWR pair in the world. The Rothera MF-radar and falling-sphere data both showed that the maximum in the summertime westwards jet occurred much lower and earlier in the season than that observed at Andoya $\left(69^{\circ} \mathrm{N}, 16^{\circ} \mathrm{E}\right)$, a similar latitude Northern Hemisphere site (Müllemann and Lübken, 2005). This difference was attributed to an atypically strong gravity-wave field over the Antarctic Peninsula and an interpretation supported by the height of the summertime zero-wind line which was observed to be around $87 \mathrm{~km}$, somewhat lower than other similar latitude Southern Hemisphere sites (e.g., Portnyagin et al., 1993). In our study, the summer time zero-wind line is found to be around $95 \mathrm{~km}$ altitude, more in line with results reported elsewhere, and significantly different from the MF-radar results reported in Hibbins et al. (2005). We note, however, that the data used in Hibbins et al. (2005) were not contemporaneous with the observations reported here, and a subsequent analysis of the Rothera MF-radar data from 2005 onwards shows a much higher summer time zero-wind line more in line with the results presented here (not shown). It is interesting to note that the MF radar data used in Hibbins et al. (2005) were recorded almost exclusively during high solar activity, whereas the data presented here is recorded during the declining phase of solar cycle 23 and the deep solar minimum between cycles. However, whether the altitude of the summertime zero-wind line is directly related to changes in solar activity remains undetermined.

Studies of mean winds in the Arctic MLT include those of Portnyagin et al. (1992, 1993, 2004, 2006), Hocking (2001), Dowdy et al. (2001, 2007a), Hall et al. (2003), Kishore et al. (2003). Again, we will not consider further the studies of Portnyagin et al. (1992) because they used meteor radar without height finding capability. Portnyagin et al. (1993, 2004, 2006), Hocking (2001), Dowdy et al. (2001, 2007a),
Hall et al. (2003), Kishore et al. (2003) used data from some or all of the following sites: Svalbard $\left(78^{\circ} \mathrm{N}, 16^{\circ} \mathrm{E}-\right.$ $\mathrm{MR})$, Troms $\varnothing\left(70^{\circ} \mathrm{N}, 19^{\circ} \mathrm{E}-\mathrm{MF}\right)$, Andenes $\left(69^{\circ} \mathrm{N}, 19^{\circ} \mathrm{E}-\right.$ $\mathrm{MF})$, Kiruna ( $\left.68^{\circ} \mathrm{N}, 20^{\circ} \mathrm{E}-\mathrm{MWR}\right)$, Esrange $\left(68^{\circ} \mathrm{N}, 21^{\circ} \mathrm{E}-\right.$ MWR), Heiss Island $\left(80^{\circ} \mathrm{N}, 58^{\circ} \mathrm{E}-\mathrm{MWR}\right)$, Dickson Island $\left(72^{\circ} \mathrm{N}, 80^{\circ} \mathrm{E}-\mathrm{MWR}\right)$, Poker Flat $\left(65^{\circ} \mathrm{N}, 213^{\circ} \mathrm{E}-\mathrm{MF}\right)$, Resolute Bay $\left(75^{\circ} \mathrm{N}, 265^{\circ} \mathrm{E}-\mathrm{MWR}\right)$ to measure the zonal and meridional winds. The type of radar is indicated by MF (Medium Frequency) or MWR (Meteor Wind Radar).

In general, the seasonal pattern of Arctic winds reported in Sect. 3.1 agrees well with those reported in the above studies. Again however, the strong wind shear towards the upper height gates $>92 \mathrm{~km}$ evident in the MWR observations tends to be much larger than those of MF observations. For example, the zonal winds over Resolute Bay (Hocking, 2001) from the MWR reach values as large as $25 \mathrm{~m} \mathrm{~s}^{-1}$ and the MWR at Esrange, presented here, reaches wind speeds of $>35 \mathrm{~m} \mathrm{~s}^{-1}$. In contrast the zonal winds at the same height and time in the MF radar studies are generally in the range $5-10 \mathrm{~m} \mathrm{~s}^{-1}$. Once more, these differences probably do not result from actual atmospheric differences, but are more likely to be a result of MWR/MF radar measurement uncertainties.

A particular focus of this study has been to compare the winds of the Antarctic and Arctic MLT region. In Sect. 3.2, a number of similarities and significant differences have been identified in the winds of the two polar regions. The earlier inter-hemispheric studies of Portnyagin et al. (1993, 2006), Dowdy et al. (2001, 2007a), Kishore et al. (2003) also suggested significant differences between the Antarctic and Arctic MLT. The similarities are that firstly, both the Antarctic and Arctic stations measure the top of the summertime westward jet between 85 and $96 \mathrm{~km}$ and eastward winds throughout the rest of the year at these heights. Secondly, the meridional winds peak, with the strongest equatorward values at heights near $88 \mathrm{~km}$. This maximum in the meridional winds is generally coincident in height with the reversal of the zonal winds (i.e., the zero-wind line).

The main difference observed between the two hemispheres, is that in the Antarctic both the zonal and meridional winds reach their maximum values near the summer solstice. However, the strongest winds in the Arctic are delayed by $\sim 1$ month compared to this. Dowdy et al. (2001) suggest that radiative effects are therefore stronger in the Antarctic and wave driving-effects are more important in the Arctic in determining the state of the summer polar MLT. Dowdy et al. (2007a) suggest that the equatorward flow near the summer mesopause $(\sim 88 \mathrm{~km})$, persists for longer in the Arctic than the Antarctic. This is also seen over Rothera and Esrange in Fig. 10a and $b$.

Kishore et al. (2003) found that the wintertime zonal winds over Davis $\left(69^{\circ} \mathrm{S}, 78^{\circ} \mathrm{E}\right)$ were nearly twice as large as those seen over Poker Flat $\left(65^{\circ} \mathrm{N}, 147^{\circ} \mathrm{W}\right)$. However, their observations covered only 2 years of data and in the observations presented here there is a high degree of interannual variability in the zonal wintertime winds. Such 
differences from year-to-year may thus not represent a climatological difference between the two polar regions. Alternatively, such differences may represent the contribution of stationary planetary wave. Kishore et al. (2003) also found that the Antarctic meridional winds were predominantly poleward throughout the year and the Arctic predominantly equatorward. In our observations, we find that both Arctic and Antarctic winds are predominantly equatorward. Again, the differences may arise because of stationary planetary waves and/or measurement biases between the MF-radar technique used by Kishore et al. and the meteor radar technique used here.

The mean-wind standard deviation plots (Figs. 5f, 6f, 71 and 81) indicate that inter-annual variability is greatest in different seasons in the two polar regions. The significantly greater level of variability evident in late winter/spring over Esrange compared to that over Rothera almost certainly reflects the major sudden stratospheric warming events that occur regularly in the Arctic, but are largely absent in the Antarctic (e.g., Hoffmann et al., 2007; Dowdy et al., 2007b). Planetary waves have been shown in modelling studies to exert a drag on the mean flow through Eliassen-Palm flux divergence (e.g., McLandress and McFarlane, 1993; Pogoreltsev, 1996). As stratospheric warmings are a disruption in the planetary wave field, they could lead to the differences observed. A possible explanation for the summertime variability over Rothera is because of the gravity wave activity which causes the reversal the zonal winds. Rothera is located on the Antarctic Peninsula and due to the relief of the land is known to be an area of intense gravity wave excitation and strong gravity wave momentum fluxes - at least in the troposphere and stratosphere (Alexander et al., 2008). Beldon and Mitchell (2009) also found significant inter-hemispheric differences in the mesopause region using the same two meteor radars. They found stronger Antarctic gravity-wave activity particularly in the spring compared with the Arctic. Variations in these fluxes could in turn result in significant variations in the momentum deposited in to the MLT, resulting in fluctuations in the zonal winds. Another possible explanation for the observed summmertime variability in the mesosphere over Rothera could come from planetary wave variability in the winter stratosphere of the northern hemisphere. Becker and Fritts (2006); Karlsson et al. (2009) both present modelling studies in which planetary-wave activity in the wintertime stratosphere causes variability in the mesopause of the opposite hemisphere through the shifting of the gravity-wave driven meridional circulation.

Our results reveal that, overall, there is a better agreement between our observations and the zonal winds of URAP than is the case for HWM-07. The zonal URAP predictions fit the observations very well during the summertime. Wintertime winds, however, do not agree so well, in both URAP and particularly HWM-07. In the case of URAP, the differences are greatest in the Antarctic winter. In the case of HWM-07 it is the Arctic winds where the most significant differences occur and the differences are significant throughout the year. There are two likely explanations of the wintertime differences. The first is the greater natural variability during this season, which probably includes significant contributions from stationary planetary waves. Stationary planetary waves will produce a longitudinally varying wind field. The observed winds may thus be somewhat different from the zonally-averaged winds of URAP. It should also be noted that these zonally-averaged winds could also contain a component of the migrating tides aliased onto them from the HRDI measurements, this could account for the differences observed since the semi-diurnal tide is known to have large amplitudes during winter. The Second is decadal scale variability in the circulation of the MLT. For example our Antarctic observations span the interval 2005-2009; whereas URAP is based on observations made between 1992 and 1995 (Such decadal scale variability has been suggested by, e.g., Portnyagin et al., 1993). In the case of the meridional winds there is generally poor agreement with HWM-07 and the strong poleward flows of the model are not observed.

Finally, we note that Portnyagin et al. (1993) suggested that there are inter-annual trends in the polar winds. They reported that the zonal winds at $\sim 95 \mathrm{~km}$ in the Antarctic exhibited a trend of decreasing speed from 1968 to 1977. This was especially noticeable in July and January. This trend was not apparent in the Arctic. They also reported maxima in meridional winds occurring when the zonal winds are at a minimum (e.g., 1971 and 1982/83 from Portnyagin et al., 1993). Such long-term trends may, in part, account for some of the differences between our observations and the other observations and models discussed above, where the various studies used different years of observation. Merzlyakov et al. (2009) also reported trends in long-term mean-wind measurements in the Antarctic. They found that there was a tendency for the winter zonal winds to decrease in amplitude between 1970 and 2006. A similar trend was found in the summertime zonal winds between 1970 and 1990, however, they found an increasing trend after, between 1993 and 2005.

We regard our Antarctic observations as being of too short in duration to make any meaningful estimate of trends in the mean winds. For the longer Arctic dataset, we carried out a linear regression analysis of the winds in each month and in each height gate (not shown). In this simple analysis, no significant tends in either the zonal or meridional winds were found.

\section{Conclusions}

Meteor radars at Rothera $\left(68^{\circ} \mathrm{S}, 68^{\circ} \mathrm{W}\right)$ and at Esrange $\left(68^{\circ} \mathrm{N}, 21^{\circ} \mathrm{E}\right)$ have been used to measure winds in the Antarctic and Arctic mesosphere and lower thermosphere region at heights of 80 to $98 \mathrm{~km}$. The inter-hemispheric comparisons suggest that there are some similarities as well as significant differences in both the zonal and meridional 
winds. The reversal of the zonal winds in summertime occurs about one month later over Rothera than over Esrange. The summertime wind shear is shifted between the two hemispheres giving stronger westward flow over Rothera and stronger eastward flow over Esrange but with very similar wind shear. The meridional winds over both sites show flow which is equatorward throughout most the year with significantly stronger equatorward flows during summer. Over Rothera the summertime jet is present over the entire height range, whereas over Esrange it is more localised in height. These differences in wind speeds and variability between the two polar regions may well originate from differences in the strength of gravity-wave driving of the mean flow and the behaviour of the Antarctic and Arctic stratospheric polar vortex, in particular sudden stratospheric warmings.

Comparisons with URAP reveal a generally good agreement in the zonal winds, although significant differences exist in the Antarctic winter where URAP winds are noticeably stronger than observed. Comparisons with HWM-07 reveals significant differences in Arctic winter where HWM07 winds are much stronger than observed. The meridional winds of HWM-07 are significantly more poleward than observed. At least some of these differences may be due to stationary planetary waves producing a longitudinally varying wind field or may reflect decadal scale changes in the MLT circulation. Evaluating the magnitude of such effects represents an interesting and important area for future study.

Acknowledgements. The authors would like to thank the teams who have working on the URAP and HWM models. This study was supported by the Science and Technology Facilities Council (STFC) of the UK. The Rothera Meteor Radar was funded under a Natural Environment Research Council (NERC) Antarctic Funding Initiative (AFI) Grant: AF15/38.

Edited by: A. Baumgaertner

\section{References}

Alexander, M. J. and Teitelbaum, H.: Observation and analysis of a large amplitude mountain wave event over the Antarctic Peninsula, J. Geophys. Res., 112, D21103, doi:10.1029/2006JD008368, 2007.

Alexander, M. J., Gille, J., Cavanaugh, C., Coffey, M., Craig, C., Eden, T., Francis, G., Halvorson, C., Hannigan, J., Khosravi, R., Kinnison, D., Lee, H., Massie, S., Nardi, B., Barnett, J., Hepplewhite, C., Lambert, A., and Dean, V.: Global estimates of gravity wave momentum flux from High Resolution Dynamics Limb Sounder observations, J. Geophys. Res., 113, D15S18, doi:10.1029/2007JD008807, 2008.

Baumgaertner, A. J. G., McDonald, A. J., Fraser, G. J., and Plank, G. E.: Long-term observations of mean winds and tides in the upper mesosphere and lower thermosphere above Scott Base, Antarctica, J. Atmos. Sol.-Terr. Phys., 67(16), 1480-1496, 2005.

Baumgaertner, A. J. G. and McDonald, A. J.: A gravity wave climatology for Antarctica compiled from Chal- lenging Minisatellite Payload/Global Positioning System (CHAMP/GPS) radio occultations, J. Geophys. Res., 112, D05103, doi:10.1029/2006JD007504, 2007.

Becker, E., and Fritts, D. C.: Enhanced gravity-wave activity and interhemispheric coupling during the MaCWAVE/MIDAS morthern summer program 2002, Ann. Geophys., 24, 1175-1188, 2006, http://www.ann-geophys.net/24/1175/2006/.

Beldon, C. L., and Mitchell, N. J.: Gravity waves in the mesopause region observed by meteor radar, 2: Climatologies of gravity waves in the Antarctic and Arctic, J. Atmos. Sol.-Terr. Phys., 71, 875-884, 2009.

Cervera, M. A. and Reid, I. M.: Comparison of simultaneous wind measurements using collocated VHF meteor radar and MF spaced antenna radar systems, Radio Sci., 30(4), 1245-1261, 1995.

Dowdy, A. J., Vincent, R. A., Igarashi, K., Murayama, Y., and Murphy, D. J.: A comparison of mean winds and gravity wave activity in the northern and southern polar MLT, Geophys. Res. Lett., 28(8), 1475-1478, 2001.

Dowdy, A. J., Vincent, R. A., Tsutsumi, M., Igarashi, K., Murayama, Y., Singer, W., and Murphy, D. J.: Polar mesosphere and lower thermosphere dynamics: 1. Mean wind and gravity wave climatologies, J. Geophys. Res., 112, D17104, doi:10.1029/2006JD008126, 2007a.

Dowdy, A. J., Vincent, R. A., Tsutsumi, M., Igarashi, K., Murayama, Y., Singer, W., Murphy, D. J., and Riggin, D. M.: Polar mesosphere and lower thermosphere dynamics: 2. Response to sudden stratospheric warmings, J. Geophys. Res., 112, D17105, doi:10.1029/2006JD008127, 2007b.

Drob, D. P., Emmert, J. T., Crowley, G., Piconem J. M., Shepherd, G. G., Skinner, W., Hays, P., Niciejewski, R. J., Larsen, M., She, C. Y., Meriwether, J. W., Hernandez, G., Jarvis, M. J., Sipler, D. P., Tepley, C. A., O'Brien, M. S., Bowman, J. R., Wu, Q., Murayama, Y., Kawamura, S., Reid, I. M., and Vincent, R. A.: An empirical model of the Earth's horizontal wind fields: HWM07, J. Geophys. Res., 113, A12304, doi:10.1029/2008JA013668, 2008.

Engler, N., Singer, W., Latteck, R., and Strelnikov, B.: Comparison of wind measurements in the troposphere and mesosphere by VHF/MF radars and in-situ techniques, Ann. Geophys., 26, 3693-3705, doi:10.5194/angeo-26-3693-2008, 2008.

Hall, C. M., Aso, T., Manson, A. H., Meek, C. E., Nozawa, S., and Tsutsumi, M.: High-latitude mesospheric mean winds: a comparison between Troms $\varnothing\left(69^{\circ} \mathrm{N}\right)$ and Svalbard $\left(78^{\circ} \mathrm{N}\right)$, J. Geophys. Res., 108(D19), 4598, doi:10.1029/2003JD003509, 2003.

Hedin, A. E., Fleming, E. L., Manson, A. H., Schmidlin, F. J., Avery, S. K., Clark, R. R., Franke, S. J., Fraser, G. J., Tsuda, T., Vial, F., and Vincent, R. A.: Empirical wind model for the upper, middle and lower atmosphere, J. Atmos. Terr. Phys., 58(13), 1421-1447, 1996.

Hibbins, R. E., Shanklin, J. D., Espy, P. J., Jarvis, M. J., Riggin, D. M., Fritts, D. C., and Lübken, F.-J.: Seasonal variations in the horizontal wind structure from $0-100 \mathrm{~km}$ above Rothera station, Antarctica $\left(67^{\circ} \mathrm{S}, 68^{\circ} \mathrm{W}\right)$, Atmos. Chem. Phys., 5, 2973-2980, doi:10.5194/acp-5-2973-2005, 2005.

Hocking, W. K. and Thyaparan, T.: Simultaneous and collocated observations of winds and tides by MF and meteor radars over London, Canada (43 N, 81 W), during 1994-1996, Radio. Sci., 
32(2), 833-865, 1997.

Hocking, W. K., Fuller B., and Vandepeer, B.: Real-time determination of meteor-related parameters utilizing modem digital technology, J. Atmos. Sol.-Terr. Phys., 63, 155-169, 2001.

Hocking, W. K.: Middle atmosphere dynamical studies at Resolute Bay over a full representative year: mean winds, tides, and special oscillations, Radio. Sci., 36(6), 1795-1822, 2001.

Hoffmann, P., Singer, W., Keuer, D., Hocking, W. K., Kunze, M., and Murayama, Y.: Latitudinal and longitudinal variability of mesosphere winds and temperatures during stratospheric warming events, J. Atmos. Sol.-Terr. Phys., 69, 2355-2366, 2007.

Holton, J. R., Curry, J. A., and Pyle, J. A.: Encyclopedia of Atmospheric Sciences, Volumes 1-6, Elsevier, 2003.

Jacobi, C., Arras, C., Kürschner, D., Singer, W., Hoffmann, P., and Keuer, D.: Comparison of mesopause region meteor radar winds, medium frequency radar winds and low frequency drifts over Germany, Adv. Space Res., 43, 247-252, 2009.

Karlsson, B., McLandress, C., and Shepherd, T. G.: Interhemispheric mesospheric coupling in a comprehensive middle atmosphere model, J. Atmos. Sol.-Terr. Phys., 71, 518-530, 2009.

Kishore, P., Namboothiri, S. P., Igarashi, K., and Murayama, Y.: Further evidence of hemispheric differences in the MLT mean wind climatology: simultaneous MF radar observations at Poker Flat $\left(65^{\circ} \mathrm{N}, 147^{\circ} \mathrm{W}\right)$ and Davis $\left(69^{\circ} \mathrm{S}, 78^{\circ} \mathrm{E}\right)$, Geo. Res. Lett., 30(6), 1336, doi:10.1029/2002GL016750, 2003.

Lieberman, R. S.: The gradient wind in the mesosphere and lower thermosphere, Earth Planets Space, 51, 751-761, 1999.

Lübken, F. J., Müllemann, A., and Jarvis, M. J.: Temperatures and horizontal winds in the Antarctic summer mesopause, J. Geophys. Res., 109, D24112, doi:10.1029/2004JD005133, 2004.

Manson, A. H., Meek, C. E., Hall, C. M., Nozawa, S., Mitchell, N. J., Pancheva, D., Singer, W., and Hoffmann, P.: Mesopause dynamics from the scandinavian triangle ofradars within the PSMOS-DATAR Project, Ann. Geophys., 22, 367386, doi:10.5194/angeo-22-367-2004, 2004.

McIntyre, M. E.: On dynamics and transport near the polar mesopause in summer, J. Geophys. Res., 94(D12), 1461714628, 1989.

McLandress, C., and McFarlane, N. A.: Interactions between Orographic Gravity Wave Drag and Forced Stationary Planetary Waves in the Winter Northern Hemisphere Middle Atmosphere, J. Atmos. Sci., 50, 1966-1990, 1993.

Merzlyakov, E. G., Murphy, D. J., Vincent, R. A., and Portnyagin, Y. I.: Long-term tendencies in the MLT prevailing winds and tides over Antarctica as observed by radar at Molodezhnaya, Mawson and Davis, J. Atmos. Sol.-Terr. Phys., 71, 21-32, 2009.

Mitchell, N. J., Pancheva, D., Middleton, H. R., and Hagan, M. E.: Mean winds and tides in the Arctic mesosphere and lower thermosphere, J. Geophys. Res., 107(A1), 1004, doi:10.1029/2001JA900127, 2002.

Müllemann, A. and Lübken, F. J.: Horizontal winds in the mesosphere at high latitudes, Adv. Space Res., 35, 1890-1894, 2005.
Pogoreltsev, A.: Simulation of the influence of stationary planetary waves on the zonally averaged circulation of the mesosphere lower thermosphere region, J. Atmos. Terr. Phys., 58, 901-909, 1996.

Portnyagin, Y. I., Forbes, J. M., Fraser, G. J., Vincent, R. A., Lysenko, I. A., and Makarov, N. M.: Dynamics of the Antarctic and Arctic mesosphere/lower thermosphere regions, Adv. Space Res., 12(10), 89-96, 1992.

Portnyagin, Y. I., Forbes J. M., Fraser G. J., Vincent R. A., Avery S. K., Lysenko I. A., and Makarov N. A.: Dynamics of the Antarctic and Arctic mesosphere and lower thermosphere regions - I. The prevailing wind, J. Atmos. Terr. Phys., 55, $827-$ 841, 1993.

Portnyagin, Y. I., Solovjova, T. V., Makarov, N. A., Merzlyakov, E. G., Manson, A. H., Meek, C. E., Hocking, W. Mitchell, N., Pancheva, D., Hoffmann, P., Singer, W., Murayama, Y., Igarashi, K., Forbes, J. M., Palo, S., Hall, C., and Nozawa, S.: Monthly mean climatology of the prevailing winds and tides in the Arctic mesosphere/lower thermosphere, Ann. Geophys., 22, 3395-3410, doi:10.5194/angeo-223395-2004, 2004

Portnyagin, Y. I., Merzlyakov, E. G., Solov'eva, T. V., and Makarov, N. A.: Interhemispheric distinctions in wind-regime parameters in the polar mesosphere-lower thermosphere, Izv. Atmos. Ocean. Phys., 42(1), 93-104, 2006.

Plane, J. M. C., Cox, R. M., and Rollason, R. J.: Metallic layers in the mesopause and low thermosphere region, Adv. Space Res. 24, 1559-1570, 1999.

Smith, A. K.: Physics and chemistry of the mesopause region, J. Atmos. Sol.-Terr. Phys., 66, 839-857, 2004.

Stubbs, T. J.: The measurement of winds in the D-region of the ionosphere by the use of partially reflected radio waves, J. Atmos. Terr. Phys., 35, 909-919, 1973.

Swinbank, R. and Ortland, D. A.: Compilation of wind data for the Upper Atmospheric Research Satellite (UARS) reference atmosphere project, J. Geophys. Res., 108(D19), 4615, doi:10.1029/2002JD003135, 2003

Vincent, R. A.: Gravity-wave motions in the mesosphere and lower thermosphere observed at Mawson, Antarctica, J. Atmos. Terr. Phys., 56(5), 593-602, 1994.

Wu, D. L., and Jiang, J. H.: MLS observations of atmospheric gravity waves over Antarctica, J. Geophys. Res., 107(D24), 4773 doi:10.1029/2002JD002390, 2002.

Younger, P. T., Astin, I., Sandford, D. J., and Mitchell, N. J.: The sporadic radiant and distribution of meteors in the atmosphere as observed by VHF radar at Arctic, Antarctic and equatorial latitudes, Ann. Geophys., 27, 2831-2841, doi:10.5194/angeo-272831-2009, 2009 